\title{
Food waste from Danish households: Generation and composition
}

Edjabou, Maklawe Essonanawe; Petersen, Claus; Scheutz, Charlotte; Astrup, Thomas Fruergaard

Published in:

Waste Management

Link to article, DOI:

10.1016/j.wasman.2016.03.032

Publication date:

2016

Document Version

Peer reviewed version

Link back to DTU Orbit

Citation (APA):

Edjabou, M. E., Petersen, C., Scheutz, C., \& Astrup, T. F. (2016). Food waste from Danish households:

Generation and composition. Waste Management, 52, 256-268. https://doi.org/10.1016/j.wasman.2016.03.032

\section{General rights}

Copyright and moral rights for the publications made accessible in the public portal are retained by the authors and/or other copyright owners and it is a condition of accessing publications that users recognise and abide by the legal requirements associated with these rights.

- Users may download and print one copy of any publication from the public portal for the purpose of private study or research.

- You may not further distribute the material or use it for any profit-making activity or commercial gain

- You may freely distribute the URL identifying the publication in the public portal 
1 Published in Waste Management

2

\section{Food waste generation and}

4 composition from Danish households

5

6 Maklawe Essonanawe Edjabou ${ }^{1 *}$, Claus Petersen $^{2}$, Charlotte

Scheutz $^{1}$, Thomas Fruergaard Astrup ${ }^{1}$

8

9

1) Department of Environmental Engineering, Technical

10 University of Denmark, 2800 Kgs. Lyngby, Denmark

11

2) Econet AS, Omøgade 8, 2.sal, 2100 Copenhagen, Denmark

12

13

14

15

*) Corresponding author: vine@env.dtu.dk;

16

Phone number: +45 45251498

17

18

19

Page 1 of $\mathbf{4 2}$ 


\section{Abstract}

21 Sustainable solutions for reduction of food waste require good understanding of food waste generation and composition,

23 including avoidable and unavoidable food waste. We analysed

$24 \quad 12$ tonnes of residual household waste collected from 1474

25 households, without source segregation of organic waste. Food

26 waste was divided into six fractions according to avoidability,

27 suitability for home composting and whether or not the food

28 waste was cooked, prepared or had been served at within the

29 household. The results showed that the residual household

30 waste generation rate was $434 \pm 18 \mathrm{~kg}$ per household per year, of

31 which $183 \pm 10 \mathrm{~kg}$ per year was food waste. Unavoidable food

32 waste amounted to $80 \pm 6 \mathrm{~kg}$ per household per year, and

33 avoidable food waste was $103 \pm 9 \mathrm{~kg}$ per household per year.

34 The mass of food waste was influenced significantly by the

35 number of occupants per household (household size) and the

36 housing type. The results also indicated that avoidable food

37 waste occurred in $97 \%$ of the households, suggesting that a

38 most of Danish households could avoid or at least reduce food

39 waste generation. Moreover, food waste including avoidable

40 and unavoidable was more likely to be found in houses

41 containing more than one person than households containing

42 only one person. 


\section{Keywords:}

46 Household food waste

47 Avoidable food waste

48 Unavoidable food waste

49 Food waste generation

50 Bootstrap and confidence interval

51

Page 3 of $\mathbf{4 2}$ 


\section{Introduction}

Food production and distribution exert increasing

54 pressure on natural resources such as land, water and energy;

55 however, one-third of the total mass of food produced is either

56 wasted or lost (Gustavsson et al., 2011). Thus, the resolution of

57 the European Parliament on resource efficiency calls on the

58 European Union (EU) Commission (EC) to set a target to

59 reduce by at least $30 \%$ the mass of food wastage in EU member

60 states by 2020 (European Parliament, 2015). Food is wasted

61 and lost throughout the food supply chain. In EU member

62 states, food waste from households is relatively higher

63 compared to other parts of the food supply chain (Brautigam et

64 al., 2014; Monier et al., 2010). For this reason, reducing food

65 waste from households may contribute significantly to meeting

66 the reduction target, as well as provide financial and energy

67 savings (Dana, 2012; WRAP, 2009). Initiatives and efforts to

68 change household behaviours related to food waste require a

69 detailed understanding of the quantities and composition of

70 what is discarded. However, although previous studies have

71 measured food waste occurring throughout the food supply

72 chain as well as from households, most of these studies have

73 provided only average data, making the description of the food

74 waste generation between households impossible. Moreover,

75 existing studies have diverse scopes and differ in their

76 definitions, metrics (e.g. mass, calories) and measurement 
77 protocols (e.g. sampling) (HLPE, 2014), making the

78 comparison of food waste data between studies challenging.

79 Therefore, there is a need to estimate accurately and

80 consistently the food waste generation and composition from

81 households (Halloran et al., 2014).

83 data collection has led to the development of various food

84 waste estimation methods, such as questionnaire surveys

85 (Abeliotis et al., 2014; Parizeau et al., 2014, Tucker and

86 Farrelly, 2015), kitchen diaries (Langley et al., 2010;

87 Silvennoinen et al., 2014; Williams et al., 2012) and literature

88 reviews based on waste statistics from public authorities

89 (Beretta et al., 2013; Brautigam et al., 2014; Gustavsson et al.,

90 2011; Monier et al., 2010). The reliability and accuracy of data

91 from these methods may be hampered by various limitations

92 and inherent errors (Hallström and Börjesson, 2013). First,

93 kitchen diaries and questionnaire surveys require a good

94 memory and the honesty of the participants, which can hardly

95 be documented (Hallström and Börjesson, 2013). Second, a

96 general ethical consideration associated with food can influence

97 the response of participants (Fessler and Navarrete, 2003). As

98 an example, Parizeau et al. (2014) reported that households in

99 Canada overestimated home cooking because it is less socially

100 acceptable "to be identified as someone who does not cook but 
101 relies on pre-packaged foods." Similarly, Quested et al. (2011)

102 estimated that food waste generation data from kitchen diaries

103 were $40 \%$ lower than when based on waste stream analysis in

104 the UK. Third, national waste statistics may be prone to

105 significant uncertainties, due to (i) varying definitions of food

106 waste and (ii) the calculation methods and assumptions applied

107 (Brautigam et al., 2014; HLPE, 2014). Therefore, waste stream

108 analysis is recommended to obtain reliable data on food waste

109 generation and composition (Dahlén and Lagerkvist, 2008;

110 Monier et al., 2010).

111 The disadvantage of the waste stream analysis is that

112 only food waste entering the municipal waste stream is

113 analysed. Thus, the waste steam analysis may exclude the food

114 waste that is fed to animals, home composted or disposed via

115 the sewer system (WRAP, 2009). Langley et al. (2010) argued

116 that the waste stream analysis characterises waste that age

117 could affect the degradation of some food products making

118 their separation and identification awkward. However, several

119 methods for characterisation of municipal solid waste

120 suggested to analyse at least one full week of waste because the

121 waste generation during weekends may differ compared to

122 weekdays (Dahlén and Lagerkvist, 2008). The degradation of

123 waste including food waste is significantly minimised when the

124 waste is sorted within a week from the sampling day (European 
125 Commission, 2004; Nordtest, 1995), which has been confirmed

126 by practical experience (Edjabou et al., 2015).

127 An additional limitation of existing food waste studies

128 is that they focus mainly on avoidable food waste (Halloran et

129 al., 2014). To provide a consistent basis for new initiatives

130 targeting households, the detailed relationship between both

131 unavoidable and avoidable food waste needed to be understood

132 (Halloran et al., 2014).

A number of studies on this subject have found a

134 correlation between the mass of avoidable food waste and the

135 number of occupants per household. However, these studies

136 had relatively small sample sizes (Langley et al., 2010;

137 Parizeau et al., 2014). Moreover, issues such as uncertainty

138 related to the influence of household size as well as

139 geographical and periodic variations on avoidable and

140 unavoidable food waste have not been systematically

141 investigated. Consequently, the statistical uncertainties related

142 to the generation of food waste and potential influencing

143 factors are poorly documented. The uncertainty related to

144 temporal variation could be reduced by sampling in different

145 periods (Dahlén and Lagerkvist, 2008).

146 The prevention of food waste has the highest

147 environmental benefits (Gentil et al., 2011). However, a

148 biological treatment of food waste (e.g. home composting, 
149 central composting, anaerobic digestion) that cannot be reduced

150 or prevented (e.g. unavoidable food waste) generates various

151 benefits, such as: (1) reduction of environmental impacts such

152 as emission of greenhouse gases, surface and groundwater

153 contamination, and soil pollution, (2) generation of nutrients

154 that will be returned to food production system, (3) production

155 of biogas (Andersen et al., 2010; Raven and Gregersen, 2007;

156 WRAP, 2009), and (4) financial incentives due to high taxes on

157 landfilling and incineration (Danish Government, 2013).

158 Currently, one of the challenges facing biogas plants

159 (e.g. in Denmark) is a reliable availability of organic material

160 (Raven and Gregersen, 2007). Therefore, availability of food

161 waste constitutes one of the key parameters for feasible

162 economic operation of biogas plants (Raven and Gregersen,

163 2007). Generally, the availability of waste materials from

164 household are also considered for planning of waste source-

165 segregation systems, and development of collection schemes

166 (Nilsson and Christensen, 2010).The availability of food waste

167 can be estimated by analysing the occurrence of food waste

168 from households (US EPA, 2002). Despite the importance of

169 these data, they were not attempts to analyse food waste

170 occurrence from households, thereby hindering our ability to

171 accurately map resources and develop food waste treatment

172 technologies. 
174 occurrence, the mass, and composition of discarded food

175 fractions from Danish households. The study also aimed at

176 evaluating and estimating the influence of the following

177 factors: (1) geographical variations (city, municipalities and

178 region), (2) periodic variations, and (3) household size, on the

179 mass and the occurrence of individual food waste fractions.

$180 \quad$ 2-Materials and methods

$181 \quad 2.1$ Definitions and classification of food waste

182 In this study, food waste includes food, drinks and

183 beverages that are avoidable and unavoidable (FUSIONS,

184 2014; WRAP, 2009). We applied the food waste classification

185 described by Edjabou et al. (2015), WRAP (2009) and

186 FUSIONS (2014). Initially, food waste was subdivided into

187 animal-derived products and vegetable products. Vegetable

188 food waste estimates the potential mass of food waste from

189 households that could be home composted, provided that in

190 home composting schemes, animal-derived may be, excluded

191 because of the risk of attracting flies, rats and other pests as

192 well as undesired odours (Christensen and Matsufuji, 2010).

193 The two food waste fractions (animal-derived and vegetable)

194 were further grouped into avoidable and unavoidable food

195 waste (FUSIONS, 2014; Koivupuro et al., 2012; Lebersorger

196 and Schneider, 2011; WRAP, 2009). Unavoidable food waste is 
197 defined as "food that is not and has not been edible under

198 normal circumstances"(WRAP, 2009), e.g. bones, carcasses,

199 egg shells, peels, fruit skin, apple cores, coffee grounds, etc.

200 (Table 1 \& Table SM 1), while avoidable food waste refers to

201 edible food that could have been eaten but instead is disposed

202 off regardless of the reason (FUSIONS, 2014). Finally,

203 avoidable food waste was split into two further fractions. The

204 first covered "food and drinks that have been cooked, prepared

205 or served in the home"(WRAP, 2009), characterised as

206 avoidable processed food waste, while the second covered

207 "purchased food that has been discarded" (WRAP, 2009) such

208 as discarded food that has not been cooked, prepared or served

209 as a meal (avoidable unprocessed food waste). As a result, we

210 had six detailed fractions: (1) "avoidable unprocessed vegetable

211 food waste" (AUVFW), (2) "avoidable processed vegetable

212 food waste" (APVFW), (3) "unavoidable vegetable food waste"

213 (UVFW), (4) "avoidable unprocessed animal-derived food

214 waste" (AUAFW), (5) “avoidable processed animal-derived

215 food waste" (APAFW) and (6) "unavoidable animal-derived

216 food waste" (UAFW) (Table 1 and Table SM 1). Table 1

217 provides an overview of what was included in these categories,

218 while Table SM 1 shows how they were grouped. For

219 comparison purposes, these categories were grouped into 11

220 food categories adapted from WRAP (2009) and Lebersorger

221 and Schneider (2011), as shown in Table 1 ( $2^{\text {nd }}$ column) and in 
222 Table SM 2. We differentiated between avoidable food waste

223 and unavoidable food waste based on the general food habit

224 and tradition in this study area. Thus, this classification may

225 change according to the food habit of the area (e.g. country,

226 region) with respect to culture, tradition, and religion. The

227 reason is there are some "food that some people eat and others

228 do not" (Beretta et al., 2013; FUSIONS, 2014; WRAP, 2009)

$229 \quad 2.2$ Study area

230 Residual household waste was sampled in five

231 municipalities in Denmark, namely Gladsaxe, Helsingør,

232 Odense, Viborg and Kolding, as shown in Table 2. In these

233 municipalities, food waste was neither source-segregated nor

234 accepted at recycling stations. Instead, along with other residual

235 waste (e.g. tissues papers, nappies, beverage cartons, plastic

236 film, metal cans, etc.), it was disposed of in residual waste bins.

237 However, gardening waste, paper, board, glass, waste electrical

238 and electronic equipment (WEEE) and batteries, household

239 hazardous waste and bulky waste were source-segregated.

240 Residual household waste management and collection

241 varied according to housing type. In single-family house areas,

242 an individual waste bin for each house was used to collect

243 residual waste, whereas, in multi-family areas, people living in

244 the same apartment block used a joint full-service collection

245 point system, with many of them sharing the same waste bin. In 
246 single-family house areas, residual waste bins consisted of

247 paper sacks and plastic bags between 110 and $240 \mathrm{~L}$ in

248 capacity, whereas in the multi-family house areas, wheeled

249 containers of 400 to $750 \mathrm{~L}$ were used. Residual household

250 waste was collected every week in the multi-family house areas

251 and every two weeks in the single-family house areas. This

252 difference between the two types of household explains the

253 waste sampling and sorting procedures applied in this study.

254 To encourage home composting, especially in the

255 single-family house areas, municipal authorities have provided

256 home composting units to those interested in doing it.

257 Additionally, the municipality of Viborg has provided these

258 composters for free, whereas other municipalities charge a fee.

\section{$259 \quad 2.3$ Sampling of residual household waste}

260 Table 2 provides an overview of the waste sampling

261 campaign in terms of numbers of households and total mass of

262 residual household waste analysed. In total, 1,474 households

263 were included in this study, and the number of households

264 investigated in each area varied between 100 and 200, as

265 recommended by Nordtest (1995). Overall, a total of 12 tonnes

266 of residual household waste was collected and manually sorted.

267 To investigate the effect of periodic variations in food waste

268 generation, residual household waste was sampled repeatedly

269 from the same single-family house area in the municipality of 
271 The households involved in this sampling campaign were

272 selected by the municipal authorities responsible for solid waste

273 management, with the aim of ensuring that these homes were

274 representative of the investigated area (Table SM 3). Before

275 sampling began, the selected households were asked if they

276 would like to participate in three waste sampling campaigns in

277 the future, without indicating the exact dates. This was done by

278 telephone and mail. First, the telephone interview was used to

279 obtain the consent of households to participate to waste

280 sampling campaign. After obtaining the consent, a confirmation

281 letter was sent to households that accepted to participate to the

282 waste sampling campaign. Based on this method, we obtained

283 up to $80 \%$ of interviewed households that accepted to

284 participate to the sampling campaign. This method was applied

285 in order to comply with Danish waste regulations (Danish EPA,

286 2014) and also to avoid any potential changes in household

287 behaviour, which could hamper the reliability of the results.

288 Thus, one week or two weeks' residual household waste was

289 collected from those households enjoying weekly existing

290 collection schedule. After sampling, the waste was transported

291 using non-compacting tipping trucks to the sorting facility. The

292 residual household waste was sorted within a week from the

293 sampling day to minimise the degradation of food products 
294 (Edjabou et al., 2015).

$295 \quad 2.4$ Food waste sorting

296 The residual household waste (Table 2) was sorted into

297 six food waste fractions and other waste material fractions. The

298 six food waste fractions were further sorted into detailed

299 fractions, which in turn were grouped into 11 food categories

300 (Table SM2).

$301 \quad$ Although the six food waste fractions were clearly

302 defined and illustrated by examples, we encountered some

303 difficulties that were overcome by sorting consistently these

304 food products throughout the sorting campaign. A food

305 product naturally composed of inseparable avoidable and

306 unavoidable components was considered as avoidable food

307 waste. For examples, a whole chicken, containing both meat

308 (avoidable) and bones (unavoidable) was sorted as

309 avoidable food waste. Similarly, whole fish, banana, etc.

310 were sorted as avoidable food waste. We differentiated

311 between processed and unprocessed food waste as follow:

312 food waste is unprocessed when the whole food product was

313 disposed with or not packaging, whereas discarded food

314 products that were partly eaten or destroyed was sorted as

315 processed food waste. Skin and peels of fruit and vegetables

316 that were removed prior disposal were sorted as unavoidable 
317 food waste..

318 The waste sorting methods involved 'batching' sorting for

319 waste from the multi-family house areas and individual waste

320 bin sorting for waste from the single-family house areas.

\section{$321 \quad 2.4 .1$ Single-family house areas}

322 In the single-family house areas, the residual waste was

323 collected separately from each household. Initially, the bins

324 were sealed tightly, to prevent losses and to separate them from

325 other bins. Finally, the waste bins were labelled with the

326 address of the household from where it was collected. The bins

327 were sorted separately, and food waste data were obtained for

328 each household. Information on the number of persons per

329 household was provided by the municipal authorities.

330 The sorting of indiviudal household waste bins enables

331 to investigate differences and distribution (Dahlén and

332 Lagerkvist, 2008), but it is very costly and demands a great

333 deal of effort. Additionally, it is only feasible in single-family

334 house areas.

$335 \quad$ 2.4.2 Multi-family house areas

336 It was neither economically nor technically feasible to

337 collect and separately sort the waste from each household in

338 these areas. Instead the waste was mixed and transported to the

339 sorting facility, where it was sorted as a 'batch' (Edjabou et al., 
340 2015). Here the waste from each area was treated as a "single

341 sample." As a result, we obtained one dataset from each of the

342 multi-family house area.

343 Batch sorting is less labour intensive and suitable for all

344 housing types. While it may avoid sampling and splitting errors

345 (Edjabou et al., 2015), it does generate data that may not

346 describe waste distribution between households.

\section{$347 \quad 2.5$ Food waste data and statistical analyses}

348 Given the waste sampling and sorting procedures,

349 distributions of food waste per household were only available

350 from the single-family house areas. However, data from multi-

351 family house areas described differences between

352 municipalities.

353 The average quantities and composition of food waste

354 were calculated as weighted average according to the

355 distribution of the Danish population as shown in Tables SM 4

356 \& SM 5 (Statistics Denmark, 2015).

357 We applied permutation tests (Kabacoff, 2011) to

358 compute $\mathrm{p}$-values. A bootstrap, applied on a robust regression,

359 was used to calculate a 95\% confidence interval and estimates

360 of measurement precision (Fox and Weisberg, 2012). A

361 permutation test and bootstrap methods were applied, because

362 they do not require distribution assumptions for the data, and

363 they are less sensitive to outliers (Kabacoff, 2011). 
was influenced by housing type, by comparing the average data

366 from each of the two areas. Furthermore, we analysed factors

367 influencing the mass of food waste in the single-family house

368 areas and compared the relationship between individual food

369 waste fractions. The households' generation of food waste was

370 analysed by means of a permutation test extended to logistic

371 regression. Here, the binary variable was whether a household

372 generated food waste (mass higher than zero) or not (the mass

373 was zero) (Kabacoff, 2011).

374 The effect of the sample size was analysed for each food

375 waste fraction by assessing the relationship between the

376 confidence intervals and the sample size (number of households).

377 The confidence intervals were computed using bootstrapping

378 (Crawley, 2005). This method was chosen because traditional

379 sampling plans assume specific classical probability distribution

380 (typically normal distribution) of either the population or of the

381 parameters of the population to be estimated. However, given the

382 heterogeneity of waste fractions, a very large sample at

383 unacceptable cost should be considered to ensure each fraction is

384 distributed normally. Moreover, the composition studies showed

385 that almost no waste fraction generation and composition is

386 normally distributed (Klee, 1993). For these reasons, traditional

387 sampling theories are not suitable to estimate the required sample 
size in order to determine the quantity or the composition of solid waste (Klee, 1993)assume specific classical probability

391 population or of the parameters of the population to be estimated.

392 However, given the heterogeneity of waste fractions, a very large

393 sample at unacceptable cost should be considered to ensure each

394 fraction is distributed normally. Moreover, the composition

395 studies showed that almost no waste fraction generation and

396 composition is normally distributed (Klee, 1993). For these

397 reasons, traditional sampling theories are not suitable to estimate

398 the required sample size in order to determine the quantity or the

399 composition of solid waste (Klee, 1993). The data were modelled using the statistical and

401 graphical software R (http://www.r-project.org).

\section{$402 \quad 3$ Results and discussion}

\section{$403 \quad 3.1$ Analysis of sample size for each municipality}

404 We simulated sample sizes (k: to determine) between 5

405 and 782, and for each sample size we used 10,000 replicates. The

406 results show that the bootstrap 95\% confidence intervals for food

407 waste fractions narrowed sufficiently to suggest that a sample

408 size of 100-200 households would produce reliable results. This

409 simulation confirms the sample size recommended by Nordtest

410 (1995).

\section{$411 \quad 3.2$ Quantities and composition of food waste fractions}


413 wet mass and the composition of food waste. Figure 1

414 illustrates the average mass of food waste generated in a Danish

415 household, split into unavoidable and avoidable, which were

416 further split into the six food waste fractions. The mass of

417 vegetable (suitable for home composting) and animal-derived

418 food waste are also provided.

The total weighted mass of residual waste generated in an average Danish household amounted to $434 \pm 18 \mathrm{~kg}$ per year

421 (Figure 1), or $201 \pm 13 \mathrm{~kg}$ per person per year. Thus, per mass,

422 the largest contribution to residual household waste was from

423 food waste $(43 \pm 1.8 \%)$ as shown in Table 3 . These results are

424 consistent with previous Danish studies, which reported $42 \%$

425 (Edjabou et al., 2015) and 41\% (Riber et al., 2009) food waste.

427 of avoidable food waste and $43.6 \pm 2.2 \%$ of unavoidable food

428 waste (Table SM 6). The avoidable food waste amounted to

$429103 \pm 9 \mathrm{~kg}$ per household per year (Figure 1), or $48 \pm 4 \mathrm{~kg}$ per

430 person per year. These results differ from those estimated by

431 EUROSTAT at $7 \mathrm{~kg}$ per person per year (Monier et al., 2010) and

$432126 \mathrm{~kg}$ per household (Brautigam et al., 2014) as shown in Table

433 5. However, Monier et al. (2010) acknowledged their estimates

434 may include high uncertainties, and so they recommended

435 undertaking a waste stream analysis to estimate reliable data. The 
mass of avoidable food waste from Danish households was also

437 lower than those found in the UK (210 kg per household per year

438 (WRAP, 2011)), the United States (124 kg per person per year

439 (Koester, 2013)) and in Canada (117 kg per person per year

440 (Parizeau et al., 2014)). However, this figure is in the range of

441 those reported in Austria (33 kg per person per year (Lebersorger

442 and Schneider, 2011)) and Finland (23 kg per person per year

443 (Koivupuro et al., 2012)). This discrepancy between countries

444 confirms the difficulty of extrapolating avoidable food waste

445 data.

Avoidable processed food waste, which occurs after

447 cooking, serving or preparation (Section 2.1) accounted for $30 \%$

448 of all avoidable food waste (Table 3 and Table SM 6) and was

$44934 \pm 5 \mathrm{~kg}$ per household per year (Figure 1), or $16 \pm 3 \mathrm{~kg}$ per person

450 per year. Avoidable unprocessed food waste constituted $67 \%$ of

451 all avoidable food waste (Table 3 and Table SM 6) and was

452 estimated at $79 \pm 9 \mathrm{~kg}$ per household (Figure1) per year, or $32 \pm 4$

$453 \mathrm{~kg}$ per person per year. These results indicate that a high

454 proportion of avoidable food waste was food that had been

455 purchased, stored (or not) and then discarded.

456 On average, $71 \%$ of the avoidable food waste consisted

457 of vegetable products, which amounted to $73 \pm 8 \mathrm{~kg}$ per household

458 per year (Figure 1), or $35 \pm 2 \mathrm{~kg}$ per person per year. The

459 corresponding $29 \%$ of avoidable animal-derived food waste 
460 indicates that Danish households discard a relatively small mass

461 avoidable animal-derived food waste compared to avoidable

462 vegetable food waste. Moreover, given that animal-derived food

463 waste consisted of animal products and a mix of animal products

464 and vegetable products, such as salads (Table 1), we could

465 conclude that the mass of avoidable animal products may be

466 smaller than the mass of avoidable animal-derived food waste.

While the mass of avoidable animal-derived food waste consisted of $50 \%$ unprocessed avoidable food waste, avoidable vegetable food waste comprised $74 \%$ of avoidable unprocessed

471 food waste (54 $\pm 6 \mathrm{~kg}$ per household per year) and $36 \%$ avoidable

472 processed food waste (19 $\pm 7 \mathrm{~kg}$ per household per year), as

473 shown in Figure 1. This result indicates that about $74 \%$ of the

474 avoidable vegetable food waste may be food that has been

475 purchased and then thrown away, without having been cooked,

476 prepared or served as a meal. These results could be explained

477 mainly by inefficient purchase planning, causing unnecessary and

478 excessive food that neither could be eaten nor preserved for a

479 longer period(FUSIONS, 2014; Halloran et al., 2014; Parizeau et

480 al., 2014; Silvennoinen et al., 2012).Thus, shopping planning

481 reduce (Silvennoinen et al., 2014; Stefan et al., 2013; WRAP,

482 2009) and the correct storage of vegetables and fruits (WRAP,

483 2009) could reduce substantially the mass of avoidable food 
484 waste in the Danish households. Additionally, recipes for food

485 leftovers and cooking planning (WRAP, 2009) should be

486 considered to reduce food waste from household.

$487 \quad 3.2$ Composition of food categories

$488 \quad$ Food waste fractions were grouped in food categories

489 (Table 1 and Table SM 2). Each food category was further

490 subdivided into avoidable and unavoidable food waste as

491 shown in Figure 2. Overall, the dominant food products were

492 fresh vegetables and salads (30\% of total food waste) and fresh

493 fruit (17\% of total food waste), followed by bakery (13\% of

494 total food waste), and drink and confectionery and desert (13\%

495 of total food waste).

The predominant avoidable food categories from

497 Danish houses were fresh vegetables and salads (14\% of total

498 food waste) and bakery (13\% of total food waste). However,

499 fresh vegetables and salads (16\% of total food waste), fresh

500 fruit (12\% of total food waste) and drink, confectionery and

501 desert (11\% of total food waste) were the dominant

502 unavoidable foods. A relatively high percentage of drink,

503 confectionery and desert in unavoidable food waste was mainly

504 due to spent coffee grounds. These results are comparable to

505 those found by WRAP (2009) for which fresh vegetables and

506 salads, drink, fresh fruit, bakery and meal (home-made and pre-

507 prepared) were dominant in the UK. 


\subsection{Occurrence of food waste}

We analysed whether a single-family household

510 generated one of the six food waste fractions or not. In this

511 section, occurrence of food waste refers to whether household

512 generated food waste fractions or not. This approach aimed to

513 assess the availability of food waste fractions generated from the

514 single-family house areas. Owing to the waste data for each

515 household, we computed the number of households where "zero

516 mass" of food waste were found in the waste bin. The analysis

517 was done for each of the six food waste fractions.

518 The occurrence of food waste from the Danish

519 households was analysed by assessing how many cases where

520 "zero mass" of food were found in the waste bins. The analysis

521 was done for each of the six food waste fractions. The percentage

522 of households (single-family house areas) that did not generate

523 food waste as function of household size is presented in Table 6.

524 The results show that $97 \%$ of households involved in this study

525 generated avoidable food waste, suggesting that this practice

526 occurs in most of Danish households. Avoidable processed food

527 waste was found in $68 \%$ of bins. Consequently, initiatives to

528 reduce avoidable food waste could be carried out at national

529 level, even though municipalities have the responsibility for the

530 management and prevention of municipal solid waste (Danish

531 EPA, 2014), as suggested by Halloran et al. (2014). Moreover, 
$53298 \%$ of household generated unavoidable food waste. These

533 figures suggest that, initiatives to reduce avoidable food waste

534 should be accompanied by other initiatives that enable efficient

535 resource recovery with minimum environmental impacts from

536 food waste that cannot be avoided.

538 influencing food waste generation (Table SM 7). The binary

539 variable was food waste generation (yes/no), where "yes" meant

540 that food waste fraction was found in the bins, and where "no"

541 meant that it was not found. The explanatory variables were

542 regions, municipalities and household size (Table SM 7).

543 The results show that only the variable household size

544 might affect significantly households' food waste generation

545 (Table 6). This suggests the likelihood that food waste is

546 generated will increase significantly according to the number of

547 occupants in the household. As a result, a house containing two

548 persons may increase this likelihood of generating food waste by

549 a factor of four, and a house containing more than two persons

550 may increase this figure by a factor of five or more.

Waste sampled from three different periods from the

552 same households showed that 94-97\% generated avoidable food

553 waste, whereas $97-98 \%$ generated unavoidable food waste

554 (Figure SM 1). The statistical analysis showed that periodic 
555 variations did not significantly affect household food waste

556 generation in this respect. The size of household significantly

557 influenced the generation of food waste from the Danish

558 households (Tables SM 8 \& SM 9).

These results suggest that an increase in the number of

560 persons per household increases the likelihood of wasting food. A

561 possible explanation for this might be that a person living alone

562 (household containing one person) tends to eat "simplified" or

563 "cold meal" consisting of bread (e.g. rye bread) with cold or fried

564 fish, cold meats, warm meats, etc..., soup, and ready meals. They

565 may also eat at work. As a result, these households may merely

566 generate food waste (Table 6), although they may generate other

567 waste materials such as packaging. However, a house containing

568 more one person may keep "classical" or "traditional" meal habit,

569 especially for dinner where warm meal or prepared food is

570 served. The process of preparing, cooking and serving food at

571 home for more than one person may increase the risk of

572 overestimation during purchasing and cooking, leading to food

573 waste generation. This uncertainty may increase when the size of

574 household increases because it is apparently more difficult to plan

575 efficiently purchasing and cooking of food that satisfy the desire

576 of all the household members. These results suggest that in the

577 single-family house areas, households with one person could

578 affect the availability of food waste for home composting and 
579 biogas plants. These plants rely on a continuous availability of

580 organic material

$581 \quad 3.4$ Factors influencing the quantity of individual food

$582 \quad$ waste fraction

583 First we analysed the significance differences in the quantity of

584 food waste between single-family and multi-family areas.

585 Second, we investigated that may influence the quantity of food

586 waste from the single-family house areas.

$587 \quad 3.4 .1$ Influence of housing type on food waste

$588 \quad$ The mass of residual household waste per household

589 was significantly higher in single-family house areas $(8.7 \pm 0.2$

$590 \mathrm{~kg}$ per household per week) than in multi-family house areas

591 (7.8 $\pm 0.1 \mathrm{~kg}$ per household per week) (Table 4). However, this

592 difference was not significant when considering the mass per

593 person. Similarly, single-family house areas generated

594 significantly higher mass of food waste, avoidable food waste

595 and unavoidable food waste per household than multi-family

596 house areas (Table 4). In contrast, considering the mass per

597 person, the mass of total food waste, avoidable and unavoidable

598 food waste was similar between single-family house areas and

599 multi-family house areas. Regardless of factors such as socio-

600 economic differences, these results may suggest that the results of

601 statistical analysis applied to the mass of food waste, depends on

602 the unit generation rates of food waste (mass of food waste per 
603 household or mass of food waste per person). This could be

604 explained by the difference in the number of occupants per

605 household, which is 2.4 for single-family house areas and 1.8 for

606 multi-family house areas (Statistics Denmark, 2015).

$607 \quad$ In the following sections (3.4.2 to 3.4.5), we investigated

608 the influence on the quantity of food waste from single-family

609 house areas, based on (1) household size, (2) municipality, (3)

610 region and (4) the difference between municipalities offering a

611 free composter for home composting and those, which do not

612 provide such a service. For the latter factor, we did not assess

613 differences in the numbers of households engaged in home

614 composting; we considered the mass of food waste per household

615 and per person.

\section{$616 \quad 3.4 .2$ Geographical variation}

617 Geographical variations include the influence of regions

618 and municipalities on the generated mass of food waste. The

619 distribution between households of the mass of avoidable and

620 unavoidable food waste as a function of household size in single-

621 family house areas is shown in Figures 3A \& 3B for mass per

622 household and Figures 3C \& 3D for mass per person. The results

623 show that geographical variations including municipalities $(\mathrm{df}=3$,

$624 \mathrm{p}>0.05)$ and regions $(\mathrm{df}=1, \mathrm{p}>0.05)$ did not make any significant

625 difference to the mass of avoidable and unavoidable food waste

626 per household and per person. Similarly, we found no significant 
627 difference in the mass of the six detailed food waste fractions,

628 respectively, between municipalities and regions in Denmark.

629 These findings indicate that the generation of avoidable food

630 waste, as well the detailed food waste fractions, were not affected

631 by geographical differences such as municipalities or regions.

\section{$632 \quad$ 3.4.3 Household size}

633 We analysed household size as a categorical explanatory

634 variable. The result showed that the mass of food waste (see

635 Table 1 and Table SM 1) per household may increase

636 significantly in line with the size of household. For the mass of

637 avoidable food waste per household, households containing one

638 person generated significantly lower avoidable food waste than

639 those containing two persons $(0.66 \mathrm{~kg}$, with a $95 \%$ confidence

640 interval of 0.23 to 1.44$)$, three persons, $(1.85 \mathrm{~kg}$, with a $95 \%$

641 confidence interval of 1.36 to 2.34 ) and four or more persons

642 (2.75 kg, with a $95 \%$ confidence interval of 2.30 to 3.12$)$, as

643 shown in Table 7. These findings are consistent with those of

644 Parizeau et al. (2014), Silvennoinen et al. (2014) and WRAP

645 (2009). Similarly, the mass of unavoidable food waste was also

646 significantly affected by household size (Table 7).

647 The mass of food waste decreased when household size

648 increased, except for avoidable processed food waste (avoidable

649 processed animal-derived food waste, avoidable processed

650 vegetable food waste and total avoidable processed food waste) 
651 (Tables SM 10 \& SM 11). For example, households containing

652 one person generated higher avoidable food waste than those

653 containing two persons, three persons and more than three

654 persons as it shown in Table 7. However, this difference was not

655 statistically significant, thereby suggesting that there was no

656 significant difference in the mass of avoidable food waste per

657 persons among households. Although these results differ from

658 those published by Parizeau et al. (2014), who found a negative

659 correlation, they are nevertheless consistent with those of WRAP

660 (2009), Katajajuuri et al.(2014), Koivupuro et al. (2012) and

661 Silvennoinen et al. (2014). In contrast, the mass of unavoidable

662 food waste per person decreased significantly in line with the

663 number of persons per household. Thus, a household containing

664 three or more may generate, respectively, $18 \mathrm{~kg}$ (a 95\%

665 confidence interval of 8 to 28) per person per year and $22 \mathrm{~kg}$ (a

$66695 \%$ confidence interval from 14 to 32 ) per person per year,

667 which is significantly lower than for one person (Table 8). This

668 discrepancy could reflect the difference in the generation of

669 avoidable and unavoidable food waste from the Danish

670 households.

671 The comparison between the mass of avoidable and

672 unavoidable food waste per household showed that on average,

673 Danish households generated $24 \mathrm{~kg}$ (95\% confidence interval

674 from 15 to 33) per household per year significantly higher 
675 avoidable food waste than unavoidable food waste. The results

676 according to household size showed that households containing

677 three or more persons generated $33 \mathrm{~kg}$ (95\% confidence interval

67816 to 52) per household per year significantly higher avoidable

679 food waste than unavoidable food waste. However, households

680 containing one and two persons generated comparable mass of

681 avoidable and unavoidable food waste. Figures 4 present the

682 bootstrap $95 \%$ confidence interval and mean of unprocessed vs.

683 processed and vegetable vs. animal-derived per household

684 (Figures 4A \& 4B) and per person (Figures 4C \& 4D). The

685 results also showed that the difference in the mass of food waste

686 generated per household, between (1) avoidable unprocessed

687 food waste and avoidable processed food waste and (2) vegetable

688 and total animal-derived food waste, increased significantly in

689 line with household size.

690 A possible explanation for these results may be that

691 households with one person may only cook food to satisfy their

692 own desire, at least less often than those with more than one

693 person. Furthermore, easy accessibility to shops enables

694 householders to make smaller purchases (Gjerris and Gaiani,

695 2013). Thus, households containing one person could purchase

696 food products that they want for themselves, even though

697 promotions and price discounts could affect the type and mass of

698 what they buy (Jahns et al., 2014).

$699 \quad 3.4 .4$ Free composter for home composting 

mass of food waste discarded in single-family house areas by comparing those municipalities offering free composter and those that do not.

The result of the permutation test showed that offering a

705 free composter did not make a significant difference to the mass

706 of food discarded by single-family households. Surprisingly, the

707 mass of vegetable food waste was not significantly influenced

708 either. These results may suggest that municipalities where free

709 composters are offered generated a comparable mass of food

710 waste compared to those that do not offer such a service. Since

711 we did not determine the number of households engaging in

712 home composting as a result of being given a free composter,

713 these results should be interpreted with caution.

714 The results showed that about $145 \pm 9 \mathrm{~kg}$ per household

715 per year could be home-composted (Figure 1) in Danish

716 households and as a result reduce $33 \pm 2 \%$ of the total residual

717 household waste. However, the current incentive via free of

718 charge composters has not made any significant differences in

719 this respect, especially for vegetable food waste. Tucker and

720 Speirs (2003) argued that negative perceptions, such as vermin,

721 flies, space, aesthetics, etc., may determine households' reticence

722 to take composting on board. They also found that factors such as

723 time and effort could influence the issue. Therefore, Tucker and 
724 Speirs (2003) suggested awareness programmes focusing on

725 changing perceptions, such as "composting does not necessarily

726 attract flies and vermin" and "composters can be beautiful."

727 Refsgaard and Magnussen (2009) proposed including

728 institutional and organisational solutions in addition to technical

729 solutions such as providing composters and financial incentives

730 to motivate households. An alternative could be a central

731 composting or combined anaerobic and aerobic treatment plant.

$732 \quad$ 3.4.5 Periodic mass of household food waste

733 The mass of food waste generated from households

734 during the three periods, and the p-values of the permutation test

735 (Kabacoff, 2011), are presented in Table 8.

736 Overall the results showed that the mass of food waste

737 generated in Danish households was not significantly different

738 between the three periods. However, only the mass of

739 unavoidable animal-derived food waste per household and per

740 person (4 to $6 \%$ of total food waste) was significantly different

741 through this time span. These results could be explained by the

742 demand for fresh food through the whole year and the modern

743 food chain that enables retailers to import out of season produce

744 (HLPE, 2014). However, in contrast to these results, another

745 study found significant monthly variations in Canada, which were

746 explained by the increased supply of fresh food in the summer

747 months at more affordable prices (Adhikari et al., 2008). 
749 function of household size, grouped per period per household

750 (Figures 5A \& 5B) and per person (Figures 5C \& 5D).

751 Concurrently, the mass of avoidable and unavoidable food waste

752 per household increased in line with the size of the household.

753 Compared to a household containing one person, the mass of

754 avoidable food waste may increase by $1.15 \mathrm{~kg}$ (with a $95 \%$

755 confidence interval of 0.76 to1.53) per week for a household

756 containing two persons, $1.72 \mathrm{~kg}$ (with a $95 \%$ confidence interval

757 of 0.40 to 2.97 ) per week for household containing three persons

758 and $2.42 \mathrm{~kg}$ (with a $95 \%$ confidence interval of 1.52 to 3.31 ) per

759 week for more than three persons. However, the mass of

760 avoidable food waste per person also increased in line with

761 household size, albeit not significantly.

762 The mass of unavoidable food waste per household

763 increased significantly in line with the number of occupants per

764 household, whereas the mass per person decreased insignificantly

765 in relation to household size (Figures 5A \& 5B). These results are

766 consistent with those found for the four municipalities (Section

$767 \quad 3.4 .2)$

768 3.4.6 Influence of household with "zero mass" of food

769 waste

The influence of household that did not generate food

771 waste during this sampling period on the outcome of statistical 
772 analyses was investigated by comparing two datasets: (1) all

773 households (in single-family house areas) included in the

774 sampling campaign and (2) those that actually generated food

775 waste. This means that households that did not generate anything

776 were excluded in the second datasets for each food waste

777 fraction.

We found a significant difference between datasets for the

779 following: avoidable processed food waste avoidable processed

780 vegetable food waste, avoidable processed animal-derived food

781 waste, avoidable unprocessed animal-derived food waste, and

782 unavoidable animal-derived food waste (Table SM 12). For these

783 waste fractions, the mass per person increased in line with the

784 size of household.. However, if we consider only the dataset for

785 households that generated food waste, we found that the mass of

786 food waste per person decreased when the household size

787 increased - as expected.

7885 Conclusions and future prospects

789 In the present study, we provided data for the occurrence,

790 the mass and the composition of food waste from Danish

791 households based on waste stream analysis.

792 The results showed that most of the Danish households

793 generated avoidable (97\% of households) and unavoidable (98\%

794 of households) food waste independently of regions,

795 municipalities and sampling period. Moreover, the occurrence of 
796 food waste generated by households was driven by household

797 size. The results indicate a Danish household containing one

798 person is less likely to generate avoidable food waste compared

799 to other household sizes.

800 We found that avoidable food waste was the predominant

801 food waste fraction, suggesting that a reduction of avoidable food

802 waste could reduce considerably the total mass of Danish residual

803 household waste. However, an efficient treatment of unavoidable

804 food waste could ensure resource recovery.

805 Although, the results showed that the mass per household

806 of food waste fractions increased in line with household size, the

807 statistical analysis revealed that there was no significant

808 difference among household sizes of the aggregated mass per

809 person for individual fractions, avoidable and unavoidable food

810 waste.

811 A combining waste stream analysis based on food

812 categories, households purchasing data, and their consumption

813 patterns-type should be considered to determine the mass of food

814 purchased and the mass of food consumed. These data could

815 provide better insight of the detailed food products that are

816 wasted from households. This information enables to develop

817 efficient and local based solution to reduce food waste from

818 households.

\section{Acknowledgments}


821 Council for financing this study via the IRMAR (Integrated

822 Resource Management \& Recovery) Project (No. 11-116775).

823 The Danish Environmental Protection Agency (EPA) and the

824 municipalities of Gladsaxe, Helsingør, Kolding, Viborg and

825 Odense are also acknowledged for their valuable support and

826 contributions. We would like to express our gratitude to the

827 Technical University of Denmark Environment's Graphic

828 group for helping with the graphs.

\section{Supplementary material (SM)}

830 Supplementary materials contain detailed food waste data used

831 for calculations and figures. SMs are divided into tables (Table

832 SM) and figures (Figure SM). 


\section{References}

836

837

838

839

840

841

842

843

844

845

846

847

848

849

850

851

852

853

854

855

856

857

858

859

860

861

862

863

864

865

866

867

868

869

870

871

872

Abeliotis, K., Lasaridi, K., Chroni, C., 2014. Attitudes and behaviour of Greek households regarding food waste prevention. Waste Management \& Research. 32, 237-240. doi:10.1177/0734242X14521681.

Adhikari, B.K., Barrington, S., Martinez, J., King, S., 2008. Characterization of food waste and bulking agents for composting. Waste Management. 28, 795-804. doi:10.1016/j.wasman.2007.08.018.

Andersen, J.K., Boldrin, a., Christensen, T.H., Scheutz, C., 2010. Greenhouse gas emissions from home composting of organic household waste. Waste Management 30, 2475-2482. doi:10.1016/j.wasman.2010.07.004.

Beretta, C., Stoessel, F., Baier, U., Hellweg, S., 2013. Quantifying food losses and the potential for reduction in Switzerland. Waste Management. 33, 764-73. doi:10.1016/j.wasman.2012.11.007.

Bernstad Sariva Schott, A., Vukicevic, S., Bohn, I., Andersson, T., 2013. Potentials for food waste minimization and effects on potential biogas production through anaerobic digestion. Waste Management \& Research. 31, 811-9. doi:10.1177/0734242X13487584

Brautigam, K.-R., Jorissen, J., Priefer, C., 2014. The extent of food waste generation across EU-27: Different calculation methods and the reliability of their results. Waste Management \& Research. 32, 683-694. doi:10.1177/0734242X14545374.

Crawley, M.J., 2005. Statistics: An Introduction using R, American Statistician. John Wiley \& Sons Ltd., London, UK. doi:10.1002/9781119941750.

Christensen, T., Matsufuji, Y., 2010. Source Segregation and Collection of Source-Segregated Waste., in: Christensen, T.H. (Ed.), Solid Waste Technology \& Management, Volume 1 \& 2. Chichester, UK. doi:10.1002/9780470666883.ch21

Dahlén, L., Lagerkvist, A., 2008. Methods for household waste composition studies. Waste Management. 28, 1100-12. doi:10.1016/j.wasman.2007.08.014. 
Dana, G., 2012. Wasted: How America is losing up to 40 percent of its food from farm to fork to landfill, Natural Resources Defense Council Issue Paper. 12-06-B.

Danish EPA, 2014. National Standard affaldsregulativer (National standard of waste regulation) [WWW Document]. URL https://www3.mst.dk/Nstar/Regulation/Search.aspx.

Danish Government, 2013. Denmark without Waste: Recycle More-Incinerate Less. Danish Ministry of the Environment, Copenhagen, Denmark

Edjabou, M.E., Jensen, M.B., Götze, R., Pivnenko, K., Petersen, C., Scheutz, C., Astrup, T.F., 2015. Municipal solid waste composition: Sampling methodology, statistical analyses, and case study evaluation. Waste Management. 36, 12-23. doi:10.1016/j.wasman.2014.11.009.

European Commission, 2004. Methodology for the Analysis of Solid Waste (SWA-tool). User Version 43, 1-57.

European Parliament, 2015. European Parliament resolution of 9 July 2015 on resource efficiency: moving towards a circular economy. [WWW Document]. URL http://www.europarl.europa.eu/sides/getDoc.do?pubRef=//EP//TEXT+TA+P8-TA-2015-

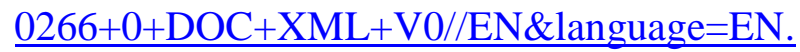

Fessler, D.M.T., Navarrete, C.D., 2003. Meat Is Good to Taboo. Journal of Cognition and Culture. 1-40. doi:http://dx.doi.org/10.1163/156853703321598563.

Fox, J., Weisberg, S., 2012. Bootstrapping Regression Models in $\mathrm{R}$, in: An R Companion to Applied Regression. SAGE, pp. 1-17.

FUSIONS, 2014. Fusion Definitional Framework for Food Waste. Final Report 3rd of July, 2014, http://www.eufusions.org/index.php/publications.

Gentil, E.C., Gallo, D., Christensen, T.H., 2011. Environmental evaluation of municipal waste prevention. Waste Manag. 31, 2371-9. doi:10.1016/j.wasman.2011.07.030.

Gjerris, M., Gaiani, S., 2013. Household food waste in Nordic countries : Estimations and ethical implications. Etikk i praksis - Nordic Journal of Applied Ethics 7, 6-23. 
935

936

937

938

939

940

941

942

943

944

945

946

947

948

949

950

Gustavsson, J., Cederberg, C., Sonesson, U., 2011. Global food losses and food waste: Extent, causes and prevention, Organization.

Halloran, A., Clement, J., Kornum, N., Bucatariu, C., Magid, J., 2014. Addressing food waste reduction in Denmark. Food Policy 49, 294-301. doi:10.1016/j.foodpol.2014.09.005.

Hallström, E., Börjesson, P., 2013. Meat-consumption statistics: reliability and discrepancy. Sustainability: Science, Practice, \& Policy. Policy 9, 37-47.

HLPE, 2014. Food losses and waste in the context of sustainable food systems - The High Level Panel of Experts(HLPE)-Report-8. Rome.

Jahns, L., Payne, C.R., Whigham, L.D., Johnson, L.K., Scheett, A.J., Hoverson, B.S., Kranz, S., 2014. Foods advertised in US weekly supermarket sales circulars over one year: a content analysis [WWW Document]. 2014. URL http://www.nutritionj.com/content/pdf/1475-2891-1395.pdf (accessed 9.29.14).

Jörissen, J., Priefer, C., Bräutigam, K.-R., 2015. Food Waste Generation at Household Level: Results of a Survey among Employees of Two European Research Centers in Italy and Germany. Sustainability 7, 2695-2715. doi:10.3390/su7032695

Kabacoff, R.I., 2011. R IN ACTION: Data analysis and graphics with R. Manning Publications Co., Shelter Island.

Katajajuuri, J.-M., Silvennoinen, K., Hartikainen, H., Heikkilä, L., Reinikainen, A., 2014. Food waste in the Finnish food chain. Journal of Cleaner Production. 73, 322-329. doi:10.1016/j.jclepro.2013.12.057.

Klee, A., 1993. NEW APPROACHES TO ESTIMATION OF SOLID-WASTE QUANTITY AND COMPOSITION. Journal of Environmental Engineering. 119, 248 - 261.

Koester, U., 2013. Total and per capita value of food loss in the United States - Comments. Food Policy 41, 63-64. doi:10.1016/j.foodpol.2013.04.003.

Koivupuro, H.-K., Hartikainen, H., Silvennoinen, K., Katajajuuri, J.-M., Heikintalo, N., Reinikainen, A., Jalkanen, L., 2012. Influence of socio-demographical, behavioural and attitudinal factors on the amount of 
964

965

966

967

968

969

970

971

972

973

974

975

976

977

978

979

980

981

982

983

984

985

986

987

988

989

avoidable food waste generated in Finnish households. International Journal of Consumer Studies. 36, 183-191. doi:10.1111/j.1470-6431.2011.01080.x.

Langley, J., Yoxall, A., Heppell, G., Rodriguez, E.M., Bradbury, S., Lewis, R., Luxmoore, J., Hodzic, A., Rowson, J., 2010. Food for thought?--A UK pilot study testing a methodology for compositional domestic food waste analysis. Waste Management \& Research. 28, 2207. doi:10.1177/0734242X08095348.

Lebersorger, S., Schneider, F., 2011. Discussion on the methodology for determining food waste in household waste composition studies. Waste Management. 31, 192433. doi:10.1016/j.wasman.2011.05.023.

Monier, V., Escalon, V., O’Connor, C., European Commission, 2010. PREPARATORY STUDY ON FOOD WASTE ACROSS EU 27 October 2010, October. doi:10.2779/85947.

Nilsson, P., Christensen, T.H., 2010. Waste Collection: Systems and Organization, in: Christensen, T.H. (Ed.), Solid Waste Technology \& Management, Volume 1 \& 2. Chichester, UK. doi:10.1002/9780470666883.ch21.

Nordtest, 1995. Municipal solid waste: Sampling and characterisation (No. NT ENVIR 001), Nordtest Method. Espoo, Finland.

Parizeau, K., von Massow, M., Martin, R., 2014. Householdlevel dynamics of food waste production and related beliefs, attitudes, and behaviours in Guelph, Ontario. Waste Management. doi:10.1016/j.wasman.2014.09.019.

Quested, T.E., Parry, a. D., Easteal, S., Swannell, R., 2011. Food and drink waste from households in the UK. Nutrition Bulletin. 36, 460-467. doi:10.1111/j.14673010.2011.01924.x.

Raven, R.P.J.M., Gregersen, K.H., 2007. Biogas plants in Denmark: successes and setbacks. Renewable \& Sustainable Energy Reviews. 11, 116-132. doi:10.1016/j.rser.2004.12.002.

Refsgaard, K., Magnussen, K., 2009. Household behaviour and attitudes with respect to recycling food waste experiences from focus groups. Journal of Environmental 
990

991

992

993

994

995

996

997

998

999

1000

1001

1002

1003

1004

1005

1006

1007

1008

1009

1010

1011

1012

1013

1014

1015

1016

1017

1018

1019

1020

1021

1022

1023

1024

1025

1026

1027

1028

Management. 90, 760-771.

doi:10.1016/j.jenvman.2008.01.018

Riber, C., Petersen, C., Christensen, T.H., 2009. Chemical composition of material fractions in Danish household waste. Waste Management. 29, 1251-7. doi:10.1016/j.wasman.2008.09.013.

Silvennoinen, K., Katajajuuri, J.-M., Hartikainen, H., Heikkilä, L., Reinikainen, A., 2014. Food waste volume and composition in Finnish households. British Food Journal. 116, 1058-1068. doi:10.1108/BFJ-12-2012-0311.

Statistics Denmark, 2015. Housing [WWW Document]. URL http://www.dst.dk/en/Statistik/emner/boligforhold.aspx (accessed 12.21.13).

Stefan, V., van Herpen, E., Tudoran, A.A., Lähteenmäki, L., 2013. Avoiding food waste by Romanian consumers: The importance of planning and shopping routines. Food Quality and Preference. 28, 375-381. doi:10.1016/j.foodqual.2012.11.001.

Tucker, P., Speirs, D., 2003. Attitudes and Behavioural Change in Household Waste Management Behaviours. Journal of Environmental Planning and Management 46, 289-307. doi:10.1080/0964056032000070927.

US EPA, 2002. RCRA Waste Sampling Draft Technical Guidance Planning, Implementation, and Assessment (No. EPA530-D-02-002), Solid Waste and Emergency Response (5305W) http://www3.epa.gov/epawaste/hazard/testmethods/sw846/ pdfs/rwsdtg_a.pdf.

Williams, H., Wikström, F., Otterbring, T., Löfgren, M., Gustafsson, A., 2012. Reasons for household food waste with special attention to packaging. Journal of Cleaner Production. 24, 141-148. doi:10.1016/j.jclepro.2011.11.044.

WRAP, 2011. New estimates for household food and drink waste in the UK A report presenting updated estimates of food and drink waste from UK.

WRAP, 2009. Household Food and Drink Waste in the UK, October. Banbury, UK. doi:10.1111/j.14673010.2011.01924.x. 
1029

Page $\mathbf{4 2}$ of $\mathbf{4 2}$ 


\section{Tables}

2 Published in Waste Management

3

4

5

6

7

8

9

10

11

12

13

14

15

16

\section{Food waste generation and composition from Danish}

\section{households}

Maklawe Essonanawe Edjabou ${ }^{1 *}$, Claus Petersen $^{2}$, Charlotte Scheutz $^{1}$, Thomas Fruergaard Astrup ${ }^{1}$ 8

1) Department of Environmental Engineering, Technical University of Denmark, 2800 Kgs. Lyngby, Denmark

2) Econet AS, Omøgade 8, 2.sal, 2100 Copenhagen, Denmark

*) Corresponding author: vine@env.dtu.dk;

Phone number: +45 45251498 
Table 1: Food categories and food products included in the six food waste fractions-Last column shows example of food products that is not included

\begin{tabular}{|c|c|c|c|}
\hline Food waste fractions & Food categories $^{\mathrm{a}}$ & Included food products & Excluded food products \\
\hline \multirow{8}{*}{$\begin{array}{l}\text { Avoidable unprocessed vegetable } \\
\text { food waste (AUVFW) }\end{array}$} & Bakery & Bread, cakes (packed or not) & Bread used for sandwiches. \\
\hline & Drinks and confectionery and desserts & Tea bags, coffee grounds, biscuits, chips, beer, alcohol, etc. & \\
\hline & Condiments, sauces, herbs and spices & Ketchup, peanut butter, sauces, salt, honey, jam, olives, mayonnaise, salt, sugar, etc. & \\
\hline & Fresh fruit & Banana, apple, melon, other fruits, etc. & Fruits prepared or served at home -half eaten. \\
\hline & Fresh vegetables and salads & Carrots, potatoes, other fresh vegetables, etc. & Home cooked or served vegetables, salad. \\
\hline & Stable food & Breakfast cereal, rice, pasta, flour, etc. & Cooked rice, pasta, etc. \\
\hline & Canned food & Corn, bean, pineapple, other tinned vegetables & \\
\hline & Other food & Other uncooked vegetable food. & \\
\hline \multirow{4}{*}{$\begin{array}{l}\text { Avoidable processed vegetable } \\
\text { food waste (APVFW) }\end{array}$} & Bakery & Vegetable pizza, pizza bread, etc. & Bread used for sandwiches, meat pizza. \\
\hline & Stable food & Rice, pasta, etc. (cooked or served at home). & \\
\hline & Fresh vegetables and salads & Potatoes, yams, vegetables, etc. (cooked or served at home). & \\
\hline & Other food & Other cooked, prepared or served food at home. & \\
\hline \multirow{6}{*}{$\begin{array}{l}\text { Unavoidable vegetable food waste } \\
\text { (UVFW) }\end{array}$} & Drinks and confectionery and desserts & Spent coffee grounds, tea bags, etc. & Unused tea bag, coffee grounds \\
\hline & Fresh fruit & Skin (e.g. pineapple), peals (e.g. banana), stones (e.g. avocado), (fruits rinds (e.g. melon). & Half eaten fruit, rotten fruit, etc. \\
\hline & Fresh vegetables and salads & Skin (e.g. potatoes, carrots, onion), peels (e.g. courgette, cucumber, etc.), etc. & Half eaten vegetables. \\
\hline & Canned food & Brine from canned vegetables food, etc. & \\
\hline & Pet food & Vegetable pet food. & \\
\hline & Other food & Other inedible vegetables and fruits. & \\
\hline \multirow{4}{*}{$\begin{array}{l}\text { Avoidable unprocessed animal } \\
\text { derived food waste (AUAFW) }\end{array}$} & Dairy and eggs & Eggs, dairy products (milk, yoghurt, cheese, margarine, butter, etc.). & Cooked eggs, opened and served dairy products. \\
\hline & Meat and fish & Meat, fish, packed cold meat, cut meat. & Opened meat package -cooked or served. \\
\hline & Canned food & Canned meat and fish, canned mixed animal and vegetable products, etc. & Opened canned vegetable. \\
\hline & Other food & Other mixed of vegetable and animal products. & Opened canned mixed or only animal products. \\
\hline \multirow{5}{*}{$\begin{array}{l}\text { Avoidable processed animal } \\
\text { derived food waste (APAFW) }\end{array}$} & Bakery & Bread found in sandwich prepared and served at home. & \\
\hline & Dairy and eggs & Cooked or fried eggs, cheese served at home, etc. and edible leftover. & \\
\hline & Canned food & Opened canned meat and fish food. & Unopened canned vegetable food. \\
\hline & Meat and fish & Cooked, prepared or served at home (meat, fish, etc.). & Unopened canned mixed or only animal products. \\
\hline & Other food & Other mixed of vegetable and animal products cooked, prepared or served at home. & \\
\hline \multirow{4}{*}{$\begin{array}{l}\text { Unavoidable animal derived food } \\
\text { waste (UAFW) }\end{array}$} & Dairy and eggs & Cheese rinds, eggs shells, etc. & Half or leftover eggs and dairy products. \\
\hline & Meat and fish & Meat and fish (skin, rinds, fat, etc.), fish heads, shellfish shells, etc. & \\
\hline & Pet food & Animal or mixed animal and vegetable pet food. & \\
\hline & Other food & Other non-edible mixed of animal and vegetable products. & \\
\hline
\end{tabular}

${ }^{\mathrm{a}}$ Grouped food categories were adapted from WRAP (2009) and Lebersorger and Schneider (2011) See Table SM 1 for food categories. 
Table 2: Number of household per area and the total amount of residual household waste generated during one week

\begin{tabular}{ccccc}
\hline Housing types & Municipalities & Regions & Number of households per sampling unit & Amount analysed (kg wet mass) $^{1}$ \\
\hline Single-family & Gladsaxe & Zealand & 111 & 1,100 \\
& Gladsaxe & Zealand & 98 & 1,100 \\
& Helsingør & Zealand & 189 & 2,000 \\
& Kolding & Jutland & 101 & 1,000 \\
& Kolding & Jutland & 93 & 1,000 \\
& Viborg & Jutland & 108 & 1,100 \\
& Viborg & Jutland & 82 & 2,100 \\
Multi-family & Gladsaxe & Zealand & 319 & 1,800 \\
& Odense & Jutland & 372 & 12,200 \\
\multicolumn{2}{c}{ Total } & - & 1,474 &
\end{tabular}

Table 3: Composition of food waste (in mass per wet basis: w/w)

\begin{tabular}{|c|c|c|c|c|c|c|}
\hline & \multicolumn{2}{|c|}{ SFHA $^{\mathrm{a}}(\mathrm{n}=7)^{\mathrm{c}}$} & \multicolumn{2}{|c|}{$\operatorname{MFHA}^{\mathrm{b}}(\mathrm{n}=3)^{\mathrm{c}}$} & \multicolumn{2}{|c|}{ Denmark (Weighted average) ${ }^{\mathrm{d}}$} \\
\hline & Mean & $\mathrm{SD}^{\mathrm{e}}$ & Mean & $\mathrm{SD}^{\mathrm{e}}$ & Mean & $\mathrm{SD}^{\mathrm{e}}$ \\
\hline \multicolumn{7}{|l|}{ Composition } \\
\hline \multicolumn{7}{|l|}{ Avoidable food waste } \\
\hline \multicolumn{7}{|l|}{ Avoidable processed food waste } \\
\hline Avoidable processed animal-derived food waste (\% w/w) & 7.8 & 1.1 & 8.9 & 3.04 & 8.2 & 1.3 \\
\hline Avoidable processed vegetable food waste $(\% \mathrm{w} / \mathrm{w})$ & 8.9 & 0.9 & 13.0 & 4.8 & 10.5 & 1.8 \\
\hline \multicolumn{7}{|l|}{ Avoidable unprocessed food waste } \\
\hline Avoidable unprocessed animal-derived food waste $(\% \mathrm{w} / \mathrm{w})$ & 8.3 & 0.8 & 7.3 & 2.3 & 8.0 & 1.0 \\
\hline Avoidable unprocessed vegetable food waste $(\% \mathrm{w} / \mathrm{w})$ & 30.6 & 1.2 & 28.5 & 7.7 & 29.8 & 2.9 \\
\hline \multicolumn{7}{|l|}{ Unavoidable food waste } \\
\hline Unavoidable animal-derived food waste $(\% \mathrm{w} / \mathrm{w})$ & 3.9 & 0.8 & 5.2 & 1.1 & 4.4 & 0.6 \\
\hline Unavoidable vegetable food waste $(\% \mathrm{w} / \mathrm{w})$ & 40.6 & 1.9 & 37.0 & 4.7 & 39.2 & 2.1 \\
\hline Total & 100 & & 100 & & 100 & \\
\hline Food waste ( $\%$ w/w of total residual household waste) & 41.0 & 0.8 & 43 & 4.7 & 43 & 1.8 \\
\hline \multicolumn{7}{|l|}{${ }^{a}$ Single-family house areas } \\
\hline \multicolumn{7}{|l|}{${ }^{b}$ Multi-family house areas } \\
\hline \multicolumn{7}{|l|}{${ }^{c}$ Number of sampling areas (see Table 1) } \\
\hline \multicolumn{7}{|c|}{$\begin{array}{l}\text { d Weighted average was calculated with 60\% single-family houses and } 40 \% \text { multi-family houses (Statistics Denmark, 2015). } \\
{ }^{e} \text { Standard deviation. }\end{array}$} \\
\hline \multicolumn{7}{|c|}{ Table 4: Generation rate of food waste (in mass per wet basis: w/w) } \\
\hline & \multicolumn{2}{|c|}{$\mathrm{SFHA}^{\mathrm{a}}(\mathrm{n}=7)^{\mathrm{c}}$} & \multicolumn{2}{|c|}{$\operatorname{MFHA}^{\mathrm{b}}(\mathrm{n}=3)^{\mathrm{c}}$} & \multicolumn{2}{|c|}{ Denmark (Weighted average) } \\
\hline & Mean & $\mathrm{SD}^{\mathrm{e}}$ & Mean & $\mathrm{SD}^{\mathrm{e}}$ & Mean & $\mathrm{SD}^{\mathrm{e}}$ \\
\hline Food waste (kg/household/week) & 3.50 & 0.1 & 3.8 & 0.2 & 3.5 & 0.1 \\
\hline Food waste (kg/person/week) & 1.47 & 0.04 & 1.97 & 0.1 & 1.6 & 0.0 \\
\hline Residual household waste (kg/household/week) & 8.71 & 0.2 & 7.81 & 0.9 & 8.4 & 0.3 \\
\hline Residual household waste ( $\mathrm{kg} /$ person/week) & 3.55 & 0.2 & 4.6 & 0.2 & 3.9 & 0.1 \\
\hline
\end{tabular}

\footnotetext{
${ }^{a}$ Single-family house areas

${ }^{b}$ Multi-family house areas

${ }^{c}$ Number of sampling areas (see Table 1)

${ }^{d}$ Weighted average was calculated with 60\% single-family houses and $40 \%$ multi-family houses (Statistics Denmark, 2015).

${ }^{e}$ Standard deviation.
} 
Table 5: Review of household avoidable food waste (wet mass basis)

\begin{tabular}{|c|c|c|c|c|}
\hline \multirow{2}{*}{ Countries } & \multicolumn{2}{|c|}{ Avoidable food waste (wet kg per year) } & \multirow{2}{*}{ Methods } & \multirow{2}{*}{ Source } \\
\hline & Household & Capita & & \\
\hline Denmark $^{a}$ & 48 & 103 & $\mathrm{WSA}^{\mathrm{a}}$ & \\
\hline UK & 210 & 88 & WSA $^{\mathrm{a}}$, diary and statistics & (WRAP, 2009) \\
\hline Austria & - & 33 & WSA $^{\mathrm{a}}$ & (Lebersorger and Schneider, 2011) \\
\hline Sweden & 60 & & WSA $^{\mathrm{a}}$ & (Bernstad Sariva Schott et al., 2013) \\
\hline $\mathrm{EU}$ & - & 115 & Database & (Brautigam et al., 2014) \\
\hline DK & - & 126 & Database & (Brautigam et al., 2014) \\
\hline Germany & - & 7 & Questionnaire & (Jörissen et al., 2015) \\
\hline Italy & - & 7 & Questionnaire & (Jörissen et al., 2015) \\
\hline Germany & - & 78 & Modelling & (Jörissen et al., 2015) \\
\hline Italy & - & $42-104$ & Modelling & (Jörissen et al., 2015) \\
\hline US & - & 124 & Literature review & (Koester, 2013) \\
\hline UK & - & 73 & Diary & (Langley et al., 2010) \\
\hline $\mathrm{EU}$ & - & 47 & Database & (Monier et al., 2010) \\
\hline Denmark & - & 7 & Database & (Monier et al., 2010) \\
\hline Finland & - & 23 & Diary & (Silvennoinen et al., 2014) \\
\hline Canada & - & 218 & $\mathrm{WSA}^{\mathrm{a}}$ & (Parizeau et al., 2014) \\
\hline
\end{tabular}

${ }^{a}$ Current study

${ }^{b}$ Waste stream analysis

Table 6: Percentage of households that did not generate food waste ("no") as function of household size (\% $\mathrm{n} / \mathrm{n})^{\mathrm{a}}$ in the single-family house area

\begin{tabular}{|c|c|c|c|c|c|}
\hline Household size & 1 person & 2 persons & 3 persons & 4+ persons & Total \\
\hline Number of households & 95 & 304 & 113 & 270 & 782 \\
\hline Avoidable food waste $(\% \mathrm{n} / \mathrm{n})$ & 11 & 3 & 0 & 13 & 3 \\
\hline Avoidable processed food waste $(\% \mathrm{n} / \mathrm{n})$ & 52 & 21 & 8 & 15 & 17 \\
\hline Avoidable processed animal-derived food waste $(\% \mathrm{n} / \mathrm{n})$ & 67 & 41 & 23 & 11 & 32 \\
\hline Avoidable processed vegetable food waste $(\% \mathrm{n} / \mathrm{n})$ & 60 & 36 & 25 & 1 & 30 \\
\hline Avoidable unprocessed food waste $(\% \mathrm{n} / \mathrm{n})$ & 15 & 5 & 2 & 14 & 4 \\
\hline Avoidable unprocessed animal-derived food waste & 49 & 28 & 19 & 1 & 25 \\
\hline Avoidable unprocessed vegetable food waste $(\% \mathrm{n} / \mathrm{n})$ & 23 & 10 & 2 & 1 & 7 \\
\hline Unavoidable food waste $(\% \mathrm{n} / \mathrm{n})$ & 5 & 2 & 0 & 1 & 2 \\
\hline Unavoidable animal-derived food waste $(\% \mathrm{n} / \mathrm{n})$ & 28 & 14 & 12 & 6 & 15 \\
\hline Unavoidable vegetable food waste $(\% \mathrm{n} / \mathrm{n})$ & 8 & 3 & 1 & 1 & 3 \\
\hline
\end{tabular}

${ }^{\mathrm{a}}$ Number of households that did not generate food waste $(n)$ divided by number of total households for each household size ( $n$ ) 
Table 7: Bootstrap estimates of standard errors and confidence intervals of the difference in amount of food waste (avoidable and unavoidable) as function of household size in single-family house areas

\begin{tabular}{|c|c|c|c|c|c|c|c|c|}
\hline \multirow[t]{2}{*}{$\begin{array}{l}\text { Household } \\
\text { size }\end{array}$} & \multicolumn{2}{|c|}{ Coefficients } & \multicolumn{2}{|c|}{ Standard Errors ${ }^{\mathrm{c}}$} & \multicolumn{2}{|c|}{$\begin{array}{l}\text { Bootstrap Confidence } \\
\text { Interval (95\%-level) per } \\
\text { household }\end{array}$} & \multicolumn{2}{|c|}{$\begin{array}{c}\text { Bootstrap Confidence }{ }^{\mathrm{a}} \\
\text { Interval (95\%-level) per person }\end{array}$} \\
\hline & Household & Person & Household & Person & Lower & Upper & Lower & Upper \\
\hline \multicolumn{9}{|c|}{ Avoidable food waste } \\
\hline 1 person & 1.03 & 1.03 & 0.15 & 0.16 & 0.81 & 1.51 & 0.81 & 1.45 \\
\hline 2 persons & $0.66^{\mathrm{b}}$ & $-0.19^{b}$ & 0.18 & 0.16 & 0.22 & 0.96 & -0.62 & 0.05 \\
\hline 3 persons & $1.85^{\mathrm{b}}$ & $-0.07^{\mathrm{b}}$ & 0.25 & 0.17 & 1.36 & 2.34 & -0.50 & 0.18 \\
\hline $4+$ persons & $2.75^{b}$ & $-0.15^{b}$ & 0.21 & 0.16 & 2.30 & 3.12 & -0.60 & 0.08 \\
\hline \multicolumn{9}{|c|}{ Unavoidable food waste } \\
\hline 1 person & 0.96 & 0.96 & 0.15 & 0.08 & 0.96 & 1.14 & 0.81 & 1.14 \\
\hline 2 persons & $0.85^{\mathrm{b}}$ & $-0.05^{\mathrm{b}}$ & 0.18 & 0.10 & 0.85 & 1.14 & -0.25 & 0.14 \\
\hline 3 persons & $0.91^{\mathrm{b}}$ & $-0.34^{\mathrm{b}}$ & 0.25 & 0.10 & 0.91 & 1.24 & -0.53 & -0.16 \\
\hline 4+ persons & $1.34^{\mathrm{b}}$ & $-0.43^{\mathrm{b}}$ & 0.21 & 0.09 & 1.35 & 1.58 & -0.62 & -0.27 \\
\hline \multicolumn{9}{|c|}{${ }^{a}$ Confidence interval that excluded zero, and indicating significant difference. } \\
\hline \multicolumn{9}{|c|}{$\begin{array}{l}{ }^{b} \text { Difference between household containing one person and other household size; }(-) \text { is lower than household containing one person and (+) means higher } \\
\text { than household containing one person. Confidence interval containing zero means that the difference is insignificant, whereas confidence interval } \\
\text { excluding zero means the difference is significant. }\end{array}$} \\
\hline
\end{tabular}

Table 8: Generation of food waste and total residual household waste in single-family house area of Gladsaxe as function of period and associated probability values from permutation test ( $\mathrm{kg}$ wet-waste per week)

\begin{tabular}{|c|c|c|c|c|c|c|c|c|}
\hline \multirow[t]{2}{*}{ Material fractions } & \multicolumn{2}{|c|}{ Period $1(n=115)^{a}$} & \multicolumn{2}{|c|}{ Period $2(n=124)^{a}$} & \multicolumn{2}{|c|}{ Period $3(n=124)^{a}$} & \multicolumn{2}{|c|}{ P-value ${ }^{\mathrm{d}}$} \\
\hline & $\mathrm{HH}^{\mathrm{b}}$ & $\mathrm{PP}^{\mathrm{c}}$ & $\mathrm{HH}^{\mathrm{b}}$ & $\mathrm{PP}^{\mathrm{c}}$ & $\mathrm{HH}^{\mathrm{b}}$ & $\mathrm{PP}^{\mathrm{c}}$ & $\mathrm{HH}^{\mathrm{b}}$ & $\mathrm{PP}^{\mathrm{c}}$ \\
\hline Avoidable food waste & $2.22 \pm 2.13$ & $0.87 \pm 0.81$ & $2.6 \pm 2.49$ & $1.01 \pm 1.34$ & $2.25 \pm 2.18$ & $0.84 \pm 0.8$ & 0.55 & 0.37 \\
\hline Avoidable processed food waste & $0.66 \pm 0.85$ & $0.24 \pm 0.29$ & $0.70 \pm 0.96$ & $0.24 \pm 0.29$ & $0.85 \pm 1.03$ & $0.31 \pm 0.39$ & 0.12 & 0.18 \\
\hline Avoidable processed animal-derived food waste ${ }^{g}$ & $0.32 \pm 0.51$ & $0.12 \pm 0.2$ & $0.33 \pm 0.43$ & $0.11 \pm 0.13$ & $0.38 \pm 0.54$ & $0.13 \pm 0.2$ & 0.34 & 0.67 \\
\hline Avoidable processed vegetable food waste ${ }^{g}$ & $0.34 \pm 0.52$ & $0.12 \pm 0.17$ & $0.37 \pm 0.74$ & $0.13 \pm 0.24$ & $0.47 \pm 0.65$ & $0.18 \pm 0.26$ & 0.22 & 0.13 \\
\hline Avoidable unprocessed food waste & $1.56 \pm 1.6$ & $0.63 \pm 0.68$ & $1.90 \pm 2.01$ & $0.77 \pm 1.27$ & $1.4 \pm 1.49$ & $0.53 \pm 0.58$ & 0.07 & 0.09 \\
\hline Avoidable unprocessed animal-derived food waste ${ }^{g}$ & $0.3 \pm 0.38$ & $0.13 \pm 0.21$ & $0.38 \pm 0.45$ & $0.15 \pm 0.18$ & $0.26 \pm 0.57$ & $0.10 \pm 0.26$ & 0.18 & 0.27 \\
\hline Avoidable unprocessed vegetable food waste ${ }^{g}$ & $1.26 \pm 1.41$ & $0.50 \pm 0.56$ & $1.52 \pm 1.81$ & $0.62 \pm 1.24$ & $1.14 \pm 1.27$ & $0.43 \pm 0.49$ & 0.14 & 0.16 \\
\hline Unavoidable food waste & $2.06 \pm 1.58$ & $0.88 \pm 0.69$ & $1.90 \pm 1.43$ & $0.77 \pm 0.53$ & $1.74 \pm 1.62$ & $0.68 \pm 0.64$ & 0.35 & 0.04 \\
\hline Unavoidable animal-derived food waste ${ }^{g}$ & $0.20 \pm 0.28$ & $0.08 \pm 0.12$ & $0.22 \pm 0.29$ & $0.08 \pm 0.09$ & $0.13 \pm 0.22$ & $0.05 \pm 0.09$ & $0.04 * f$ & $0.04 * f$ \\
\hline Unavoidable vegetable food waste ${ }^{g}$ & $1.87 \pm 1.46$ & $0.80 \pm 0.64$ & $1.68 \pm 1.34$ & $0.69 \pm 0.51$ & $1.60 \pm 1.5$ & $0.62 \pm 0.58$ & 0.17 & 0.19 \\
\hline Food waste & $4.28 \pm 3.05$ & $1.75 \pm 1.19$ & $4.49 \pm 3.38$ & $1.78 \pm 1.54$ & $3.99 \pm 3.43$ & $1.51 \pm 1.27$ & 0.46 & 0.39 \\
\hline Residual household waste & $8.86 \pm 4.64$ & $3.76 \pm 2.13$ & $9.38 \pm 5.2$ & $3.84 \pm 2.3$ & $8.62 \pm 5.64$ & $3.47 \pm 2.53$ & 0.62 & 0.84 \\
\hline \multicolumn{9}{|c|}{${ }^{a}$ Number of households in the single family house areas } \\
\hline \multicolumn{9}{|c|}{${ }^{b}$ mean and standard deviation in kg wet waste per household per week } \\
\hline \multicolumn{9}{|c|}{${ }^{c}$ mean and standard deviation in $\mathrm{kg}$ wet waste per person per week. Standard deviation describes the variation between single-family houses } \\
\hline \multicolumn{9}{|c|}{$d: p$-values for the permutation test based on the amount of $F W$ per households $(H H)$ and per person $(P P)$. } \\
\hline
\end{tabular}


Page 6 of 6 


\section{Figures}

Figure 1: Weighted generation rate of food waste in Danish households in $\mathrm{kg}$ wet mass per household per year.

Figure 2: Weighted average composition of Danish household food waste (\% mass per wet basis) based on food categories.

Figure 3: Distribution of the generation of avoidable and unavoidable food waste (box plots are based on wet mass basis) in the single family house areas as function of household size for the four municipalities: kg waste per household (A \& B) and waste kg per person per week (C\&D).

Figure 4: Comparison of the generation rates for different food waste fractions generated in singlefamily house areas between (wet mass basis of mean and 95\% confidence interval are displayed): 1) unprocessed versus processed food waste fractions (A \& C); 2) vegetable and animal-derived food waste fractions (B \& D). The data are expressed in $\mathrm{kg}$ per household per week (A \& B) and $\mathrm{kg}$ per person per week (C\&D).

Figure 5: Periodic generation of avoidable and unavoidable food waste (box plots are based on wet mass basis) in the single-family house areas of Gladsaxe as function of household size: $\mathrm{kg}$ per household (A \& B) and $\mathrm{kg}$ per person(C \& D). 


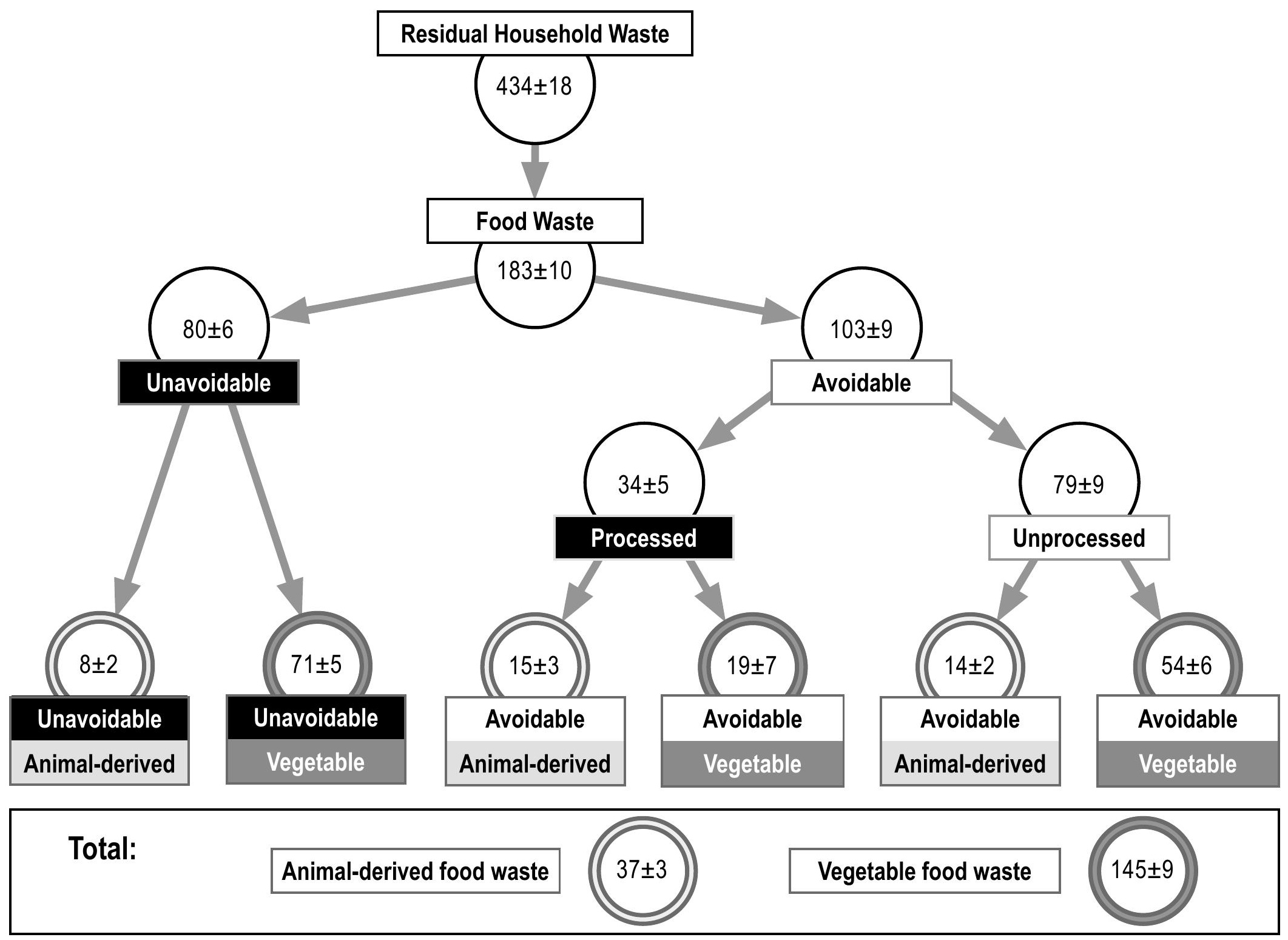




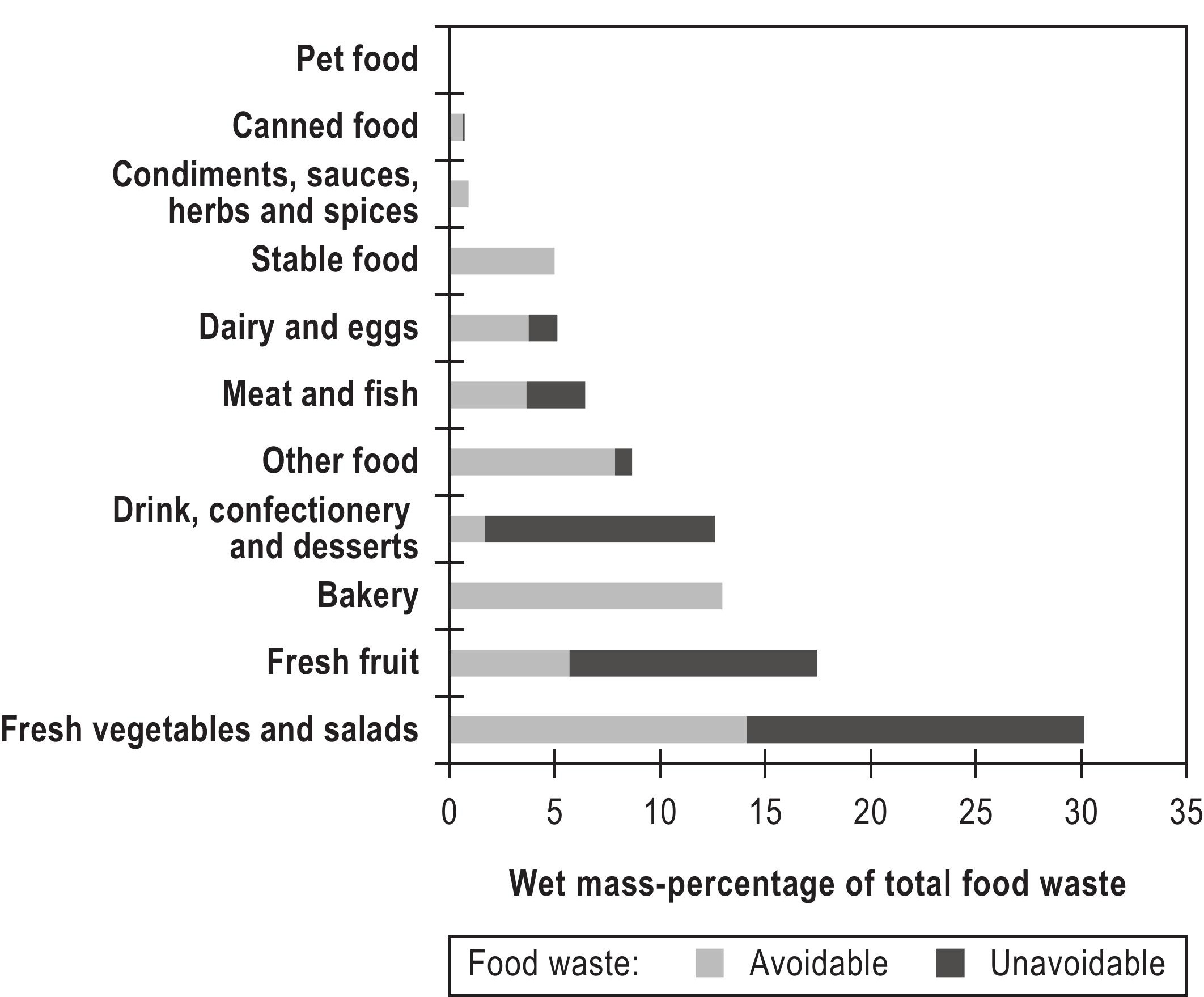

Food waste: $\quad$ Avoidable $\square$ Unavoidable

Fresh vegetables and salads 

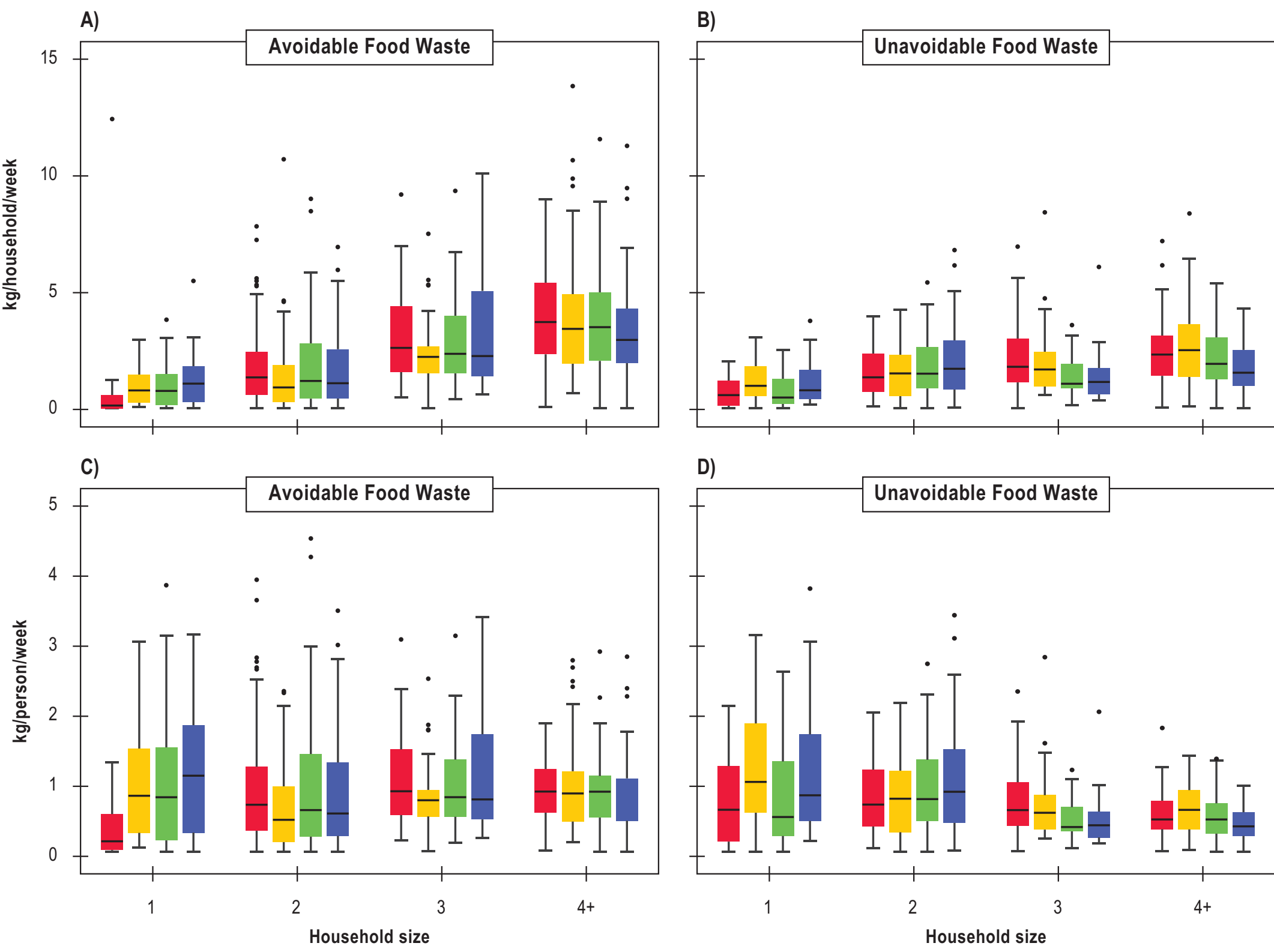

D)

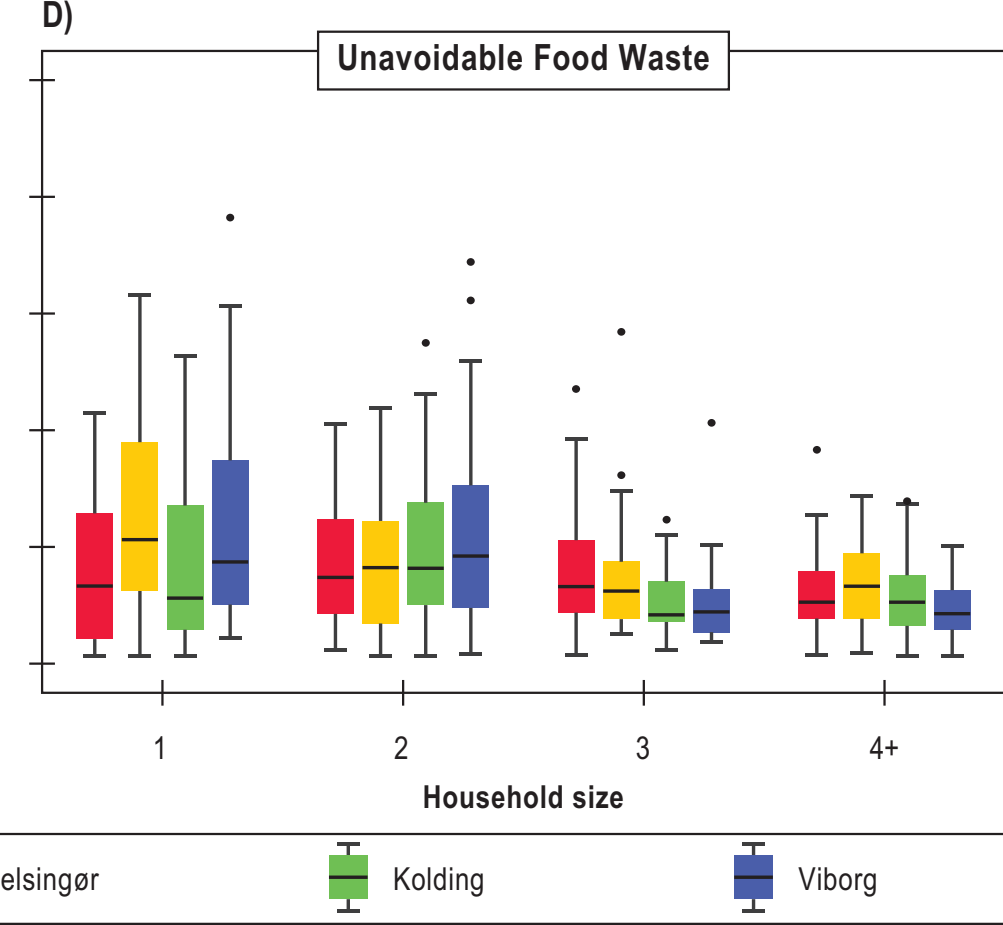


Figure 4
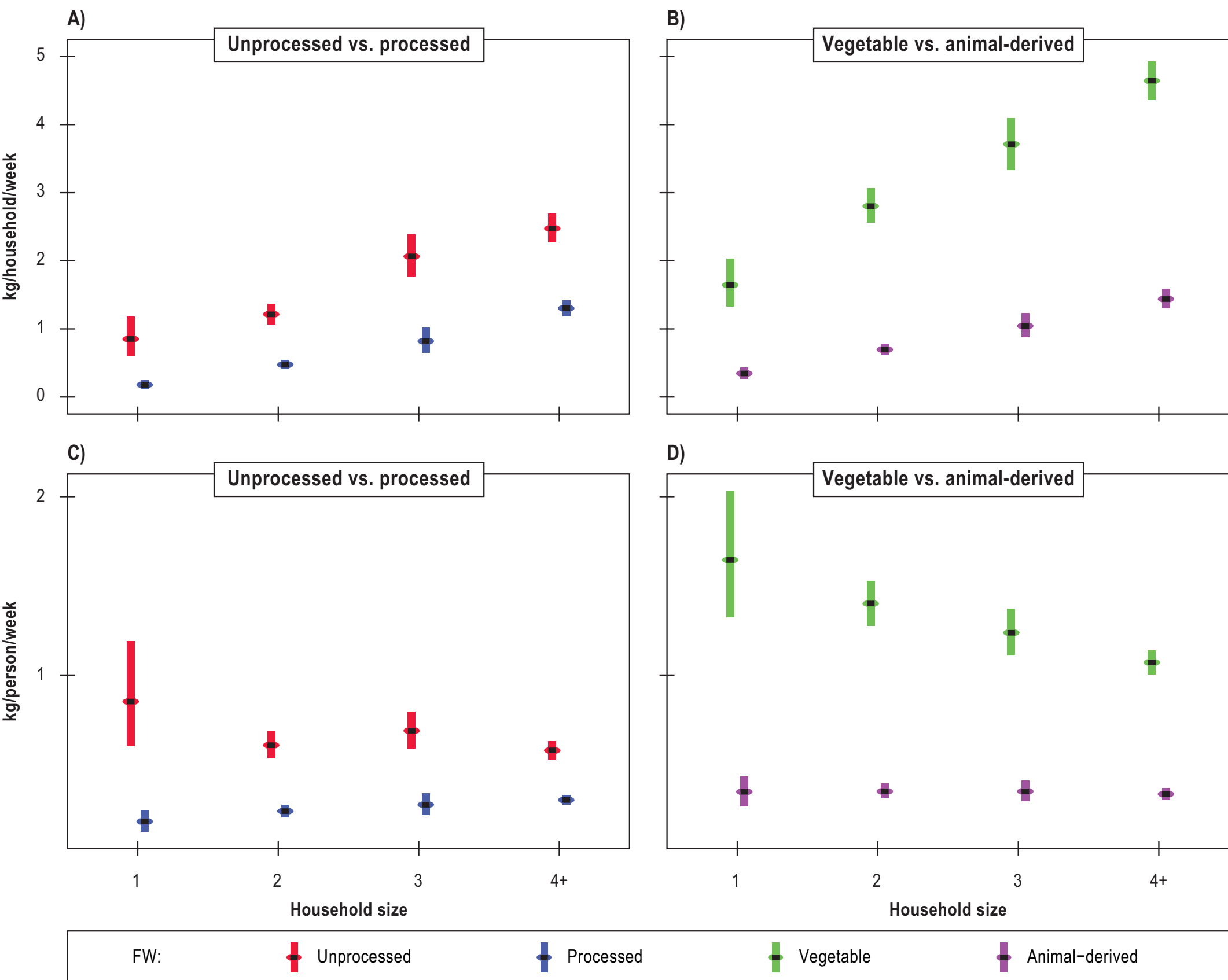


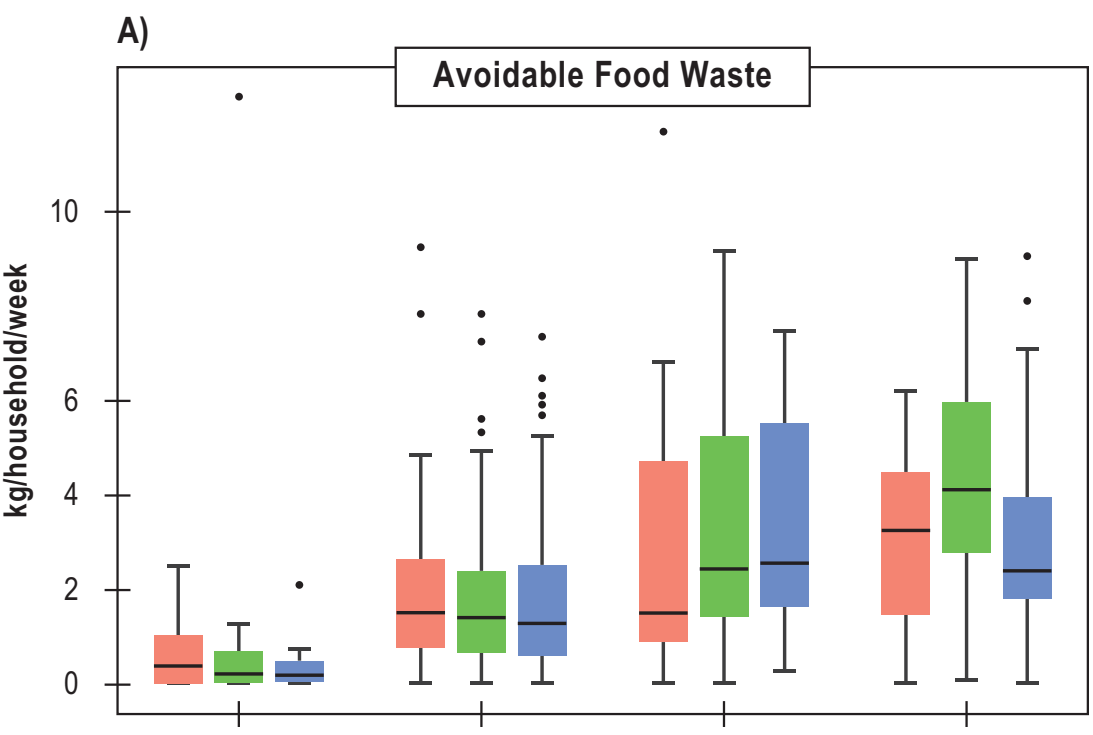

B)
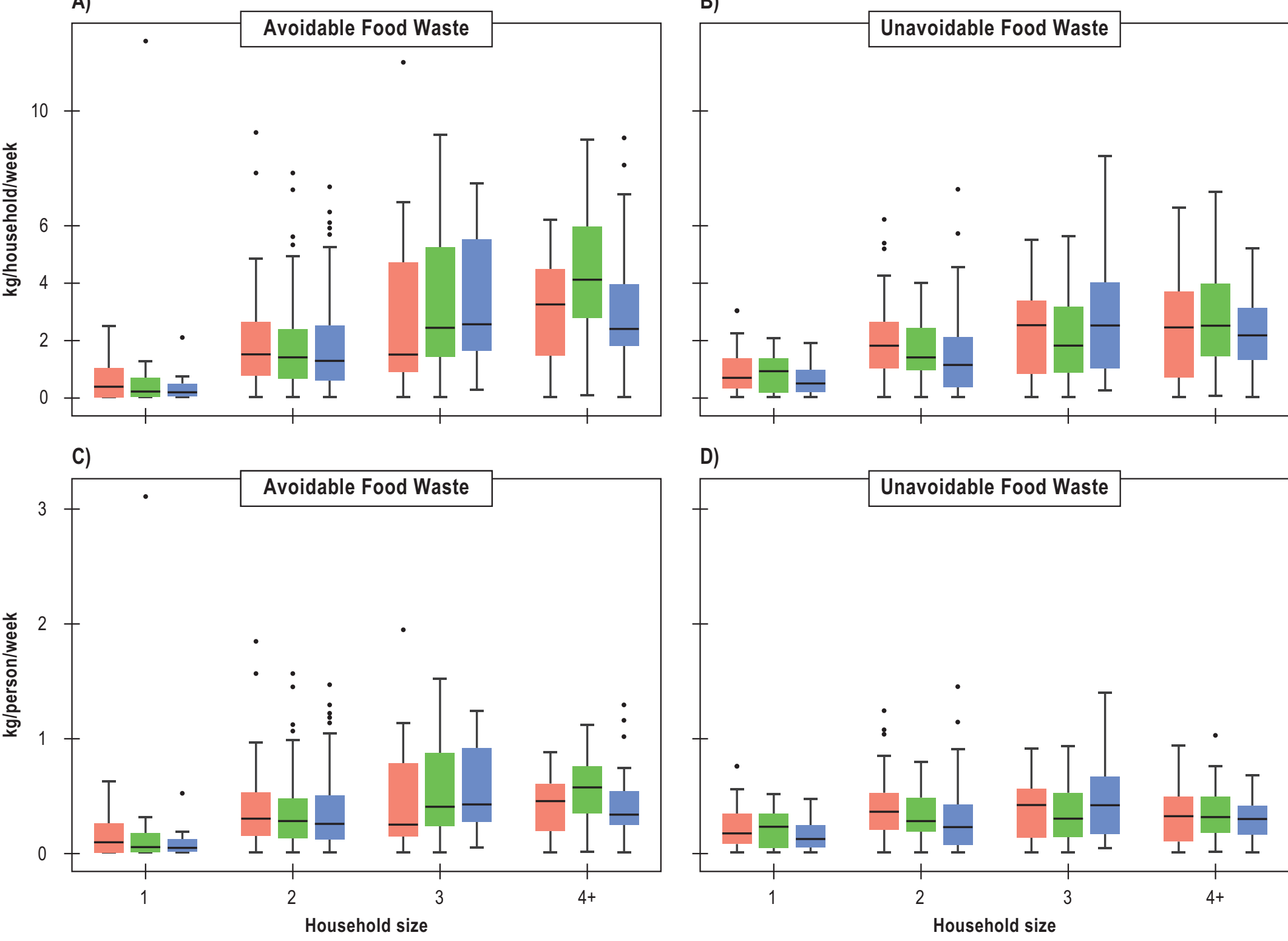

D)

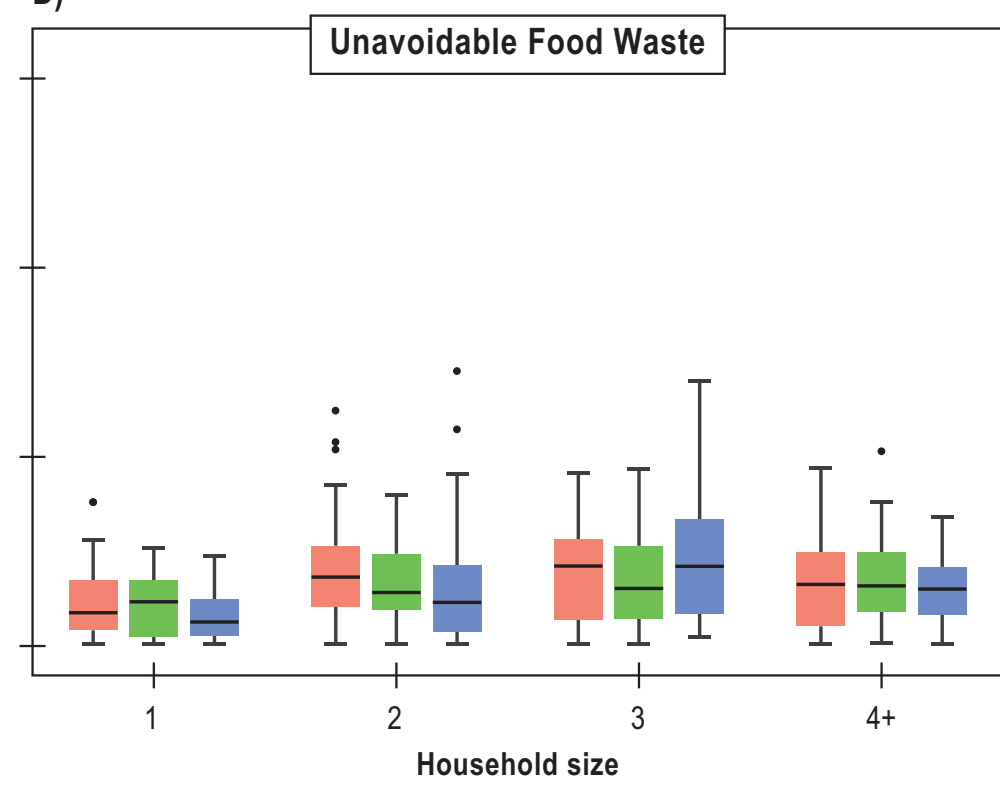


1 Supplementary materials for the paper:

2

\section{Food waste generation and composition fom Danish households}

4

5

6

7

8

9

10

11

12

13

14

15
*) Corresponding author: vine@env.dtu.dk;

Phone number: +45 45251498 


\section{Supplementary materials (SM)}

17 Supplementary materials contain detailed food waste data used for calculations. SMs are divided into 18 tables (Table SM) and figures (Figure SM). 
20 Supplementary materials (SM) - Tables

23 Table SM1: Grouping of food waste fractions

\begin{tabular}{|c|c|c|c|c|c|c|}
\hline Food waste sub-fractions & $\mathrm{APAFW}^{\mathrm{a}}$ & AUAFW & $\mathrm{UAFW}^{\mathrm{c}}$ & APVFW $^{\mathrm{d}}$ & AUVFW $^{\mathrm{e}}$ & UVFW $^{\mathrm{f}}$ \\
\hline Avoidable food waste & $\mathrm{X}$ & $\mathrm{X}$ & & $\mathrm{X}$ & $\mathrm{X}$ & \\
\hline Unavoidable food waste & & & $\mathrm{X}$ & & & $\mathrm{X}$ \\
\hline Animal derived food waste & $\mathrm{X}$ & $\mathrm{X}$ & $\mathrm{X}$ & & & \\
\hline Vegetable food waste & & & & $\mathrm{X}$ & $\mathrm{X}$ & $\mathrm{X}$ \\
\hline Avoidable processed food waste & $\mathrm{X}$ & & & $\mathrm{X}$ & & \\
\hline Avoidable unprocessed food waste & & $\mathrm{X}$ & & & $\mathrm{X}$ & \\
\hline Food waste & $\mathrm{X}$ & $\mathrm{X}$ & $X$ & $\mathrm{X}$ & $X$ & $X$ \\
\hline
\end{tabular}

$24 \quad{ }^{a}$ Avoidable processed animal derived food waste.

$25{ }^{b}$ Avoidable unprocessed animal derived food waste.

$26{ }^{c}$ Unavoidable processed animal derived food waste.

$27{ }^{e}$ Avoidable processed vegetable food waste.

$28{ }^{f}$ Avoidable unprocessed vegetable food waste. 
Table SM 2: Food waste categories and fractions included

\begin{tabular}{|c|c|}
\hline Grouped food categories & What it includes \\
\hline \multirow[t]{3}{*}{ Bakery } & Bread found in sandwich prepared and served at home \\
\hline & Bread, cakes (packed or not) \\
\hline & Vegetable pizza, pizza bread, etc. \\
\hline \multirow[t]{5}{*}{ Canned food } & Brine from canned vegetables food, etc. \\
\hline & Canned meat and fish, \\
\hline & Canned mixed animal and vegetable products, etc. \\
\hline & Corn, bean, pineapple, other tinned vegetables \\
\hline & Opened canned meat and fish food \\
\hline \multirow[t]{3}{*}{ Condiments, sauces, herbs and spices } & Honey, jam, olives, etc. \\
\hline & Mayonnaise, Ketchup, \\
\hline & Peanut butter, sauces, salt, sugar \\
\hline \multirow[t]{4}{*}{ Dairy and eggs } & Cheese rinds, eggs shells, etc., \\
\hline & Cooked or fried eggs, cheese served at home, etc. and edible leftover, \\
\hline & Dairy products (milk, yoghurt, cheese, margarine, butter, etc.) \\
\hline & Eggs, \\
\hline \multirow[t]{3}{*}{ Drinks and confectionery and desserts } & Biscuits, chips, beer, alcohol, etc \\
\hline & Spent coffee grounds, tea bags, etc. \\
\hline & Tea bags, coffee grounds \\
\hline \multirow[t]{3}{*}{ Fresh fruit } & Banana, apple, melon, other fruits, etc. \\
\hline & Skin (e.g. pineapple), peals (e.g. banana), \\
\hline & Stones (e.g. avocado), (fruits rinds (e.g. melon) \\
\hline \multirow[t]{4}{*}{ Fresh vegetables and salads } & Carrots, potatoes, other fresh vegetables, etc. \\
\hline & Peels (e.g. courgette, cucumber, etc.), etc. \\
\hline & potatoes, yams, vegetables, etc. (cooked or served at home) \\
\hline & Skin (e.g. potatoes, carrots, onion) \\
\hline \multirow[t]{4}{*}{ Meat and fish } & Cooked, prepared or served at home (meat, fish, etc.) \\
\hline & Fish heads, shellfish shells, etc. \\
\hline & Meat and fish (skin, rinds, fat, etc.), \\
\hline & Meat, fish, packed cold meat, cut meat, \\
\hline \multirow[t]{5}{*}{ Other food } & Other cooked, prepared or served food at home, \\
\hline & Other inedible vegetables and fruits \\
\hline & Other mixed of vegetable and animal products \\
\hline & Other mixed of vegetable and animal products cooked, prepared or served at home \\
\hline & Other uncooked vegetable food \\
\hline \multirow[t]{2}{*}{ Pet food } & Animal or mixed animal and vegetable pet food \\
\hline & Vegetable pet food \\
\hline \multirow[t]{2}{*}{ Stable food } & Breakfast cereal, rice, pasta, flour, etc. \\
\hline & Rice, pasta, etc. (cooked or served at home) \\
\hline
\end{tabular}

Table SM 3: Distribution of household size of both households sampled and population for the four municipalities

\begin{tabular}{|c|c|c|c|c|c|c|}
\hline \multirow{2}{*}{ Municipalities } & \multirow{2}{*}{ Type of population } & \multicolumn{4}{|c|}{ Household size (in \%) } & \multirow{2}{*}{ Total } \\
\hline & & 1 & 2 & 3 & $4+$ & \\
\hline \multirow{2}{*}{ Gladsaxe } & Sample & 12 & 36 & 16 & 35 & 100 \\
\hline & Population & 22 & 33 & 16 & 29 & 100 \\
\hline \multirow{2}{*}{ Helsingør } & Sample & 9 & 42 & 16 & 33 & 100 \\
\hline & Population & 23 & 36 & 15 & 26 & 100 \\
\hline \multirow{2}{*}{ Kolding } & Sample & 16 & 35 & 15 & 34 & 100 \\
\hline & Population & 24 & 38 & 14 & 25 & 100 \\
\hline \multirow{2}{*}{ Viborg } & Sample & 11 & 43 & 10 & 36 & 100 \\
\hline & Population & 26 & 37 & 13 & 24 & 100 \\
\hline
\end{tabular}


Table SM 4: Household size and distribution of Danish households per housing type

\begin{tabular}{lccc}
\hline Parameters & Single-family house (SFHA) & Multi-family house (MFSA) & Denmark (DK) \\
\hline Distribution (\%) & $60^{\text {aj }}$ & $40^{\text {aj }}$ & 100 \\
Average household size (Number of person per household) & 1.89 & 1.66 & $1.70^{\mathrm{b}}$ \\
\hline
\end{tabular}

Source: (Statistics Denmark, 2015)

The average amount per household in Denmark is: $M_{D K}\left(H_{\text {Household }}\right)=$ ai $M_{S F H A}+$ aj $M_{M F H A} ; M_{D K}\left(\right.$ Person $=b_{D K}\left(H_{o u s e h o l d}\right)$

Table SM 5: Distribution of Danish household's size in the single-family household area

\begin{tabular}{|c|c|c|c|c|}
\hline Household size (Number of person per households) & 1 & 2 & 3 & $4+$ \\
\hline Single-family households (SFHA) & $27^{\mathrm{cj}}$ & $38^{\mathrm{cj}}$ & $14^{\mathrm{cj}}$ & $22^{\mathrm{cj}}$ \\
\hline
\end{tabular}

The average amount per household in Denmark is: $\mathrm{M}_{\mathrm{SFHA}}=\sum_{k=1}^{n} \mathrm{c}_{k} \mathrm{~m}_{\mathrm{SFHA}(k)}$

Where ck is the distribution according to housing size, and mSFHA is the mass for each housing size.

Table SM 6: Average food waste composition (wet mass basis) for each housing type and the weighted average for Denmark

\begin{tabular}{|c|c|c|c|c|c|c|}
\hline \multirow[t]{2}{*}{ Food waste } & \multicolumn{2}{|c|}{$\mathrm{SFHA}^{\mathrm{a}}(\mathrm{n}=4)^{\mathrm{c}}$} & \multicolumn{2}{|c|}{$\operatorname{MFHA}^{\mathrm{b}}(\mathrm{n}=3)^{\mathrm{c}}$} & \multicolumn{2}{|c|}{ Denmark (Weighted Average) $^{\mathrm{d}}$} \\
\hline & Mean & $\mathrm{SD}^{\mathrm{e}}$ & Mean & $\mathrm{SD}^{\mathrm{e}}$ & Mean & $\mathrm{SD}^{\mathrm{e}}$ \\
\hline Avoidable food waste & 55.6 & 2.0 & 57.8 & 9.8 & 56.4 & 3.8 \\
\hline Avoidable processed food waste & 16.7 & 1.4 & 22.0 & 5.7 & 18.7 & 2.2 \\
\hline Avoidable processed animal-derived food waste & 7.8 & 1.1 & 8.9 & 3.0 & 8.2 & 1.3 \\
\hline Avoidable processed vegetable food waste & 8.9 & 0.9 & 13.0 & 4.8 & 10.5 & 1.8 \\
\hline Avoidable unprocessed food waste & 38.9 & 1.4 & 35.9 & 8.0 & 37.7 & 3.0 \\
\hline Avoidable unprocessed animal-derived food waste & 8.3 & 0.8 & 7.3 & 2.3 & 8.0 & 1.0 \\
\hline Avoidable unprocessed vegetable food waste & 30.6 & 1.2 & 28.5 & 7.7 & 29.8 & 2.9 \\
\hline Unavoidable food waste & 44.4 & 2.1 & 42.2 & 4.8 & 43.6 & 2.2 \\
\hline Unavoidable animal-derived food waste & 3.9 & 0.8 & 5.2 & 1.1 & 4.4 & 0.6 \\
\hline Unavoidable vegetable food waste & 40.6 & 1.9 & 37.0 & 4.7 & 39.2 & 2.1 \\
\hline Animal-derived food waste & 20.0 & 1.6 & 21.4 & 4.0 & 20.5 & 1.7 \\
\hline Vegetable food waste & 80.0 & 2.4 & 21.4 & 10.2 & 79.5 & 4.0 \\
\hline Avoidable vegetable food waste & 38.9 & 1.5 & 35.9 & 9.1 & 37.7 & 3.4 \\
\hline Avoidable animal-derived food waste & 16.7 & 1.4 & 22.0 & 3.8 & 18.7 & 1.6 \\
\hline
\end{tabular}

Avoidable animal-derived food waste

a Single-family house areas

${ }^{b}$ Multi-family house areas

${ }^{c}$ Number of sampling areas (see Table 1)

${ }^{d}$ Weighted average was calculated with $60 \%$ single-family houses and $40 \%$ multi-family houses (Statistics Denmark, 2015).

e Standard deviation quantifies the amount of dispersion of data set, which consists of the average waste values of the municipalities.

Table SM 7: Names of variables and description for logistic regression model

\begin{tabular}{lll}
\hline Response variable $(\mathrm{Y})$ & Influencing factors (explanatory) & Description \\
\hline Y=0 (FWs was not found in the RHW waste bin) & Region (categorical $\mathrm{n}=2$ ) & Jutland, Zealand \\
$\mathrm{Y}=1$ (FWs was found in the RHW waste bin) & Municipalities (categorical $\mathrm{n}=4)$ & Gladsaxe, Helsingør, Kolding and \\
& Viborg & 1 person, 1+persons \\
& Household size (categorical $\mathrm{n}=2)$ & Number of person per household \\
\hline
\end{tabular}


56 Table SM 8: Overview of the result from the logistic regression model assessing factors that influence whether 57 a Danish household generate

\begin{tabular}{|c|c|c|c|c|c|}
\hline Potential influential factors & Municipalities & Regions & Composting & Household size & Household size \\
\hline Type of variables & Categorical & Categorical & Categorical & Categorical & Continuous \\
\hline Degree of freedom & 3 & 1 & 1 & 1 & 1 \\
\hline Avoidable food waste & Not(Sig) & Not(Sig) & Not(Sig) & Sig*** & Sig*** \\
\hline Avoidable processed food waste & Not(Sig) & - & Not(Sig) & Sig* & Sig* \\
\hline Avoidable processed animal-derived food waste & Not(Sig) & $\operatorname{Not}(\mathrm{Sig})$ & Sig*** & Sig*** & Sig*** \\
\hline Avoidable processed vegetable food waste & Not(Sig) & Not(Sig) & Sig*** & $\mathrm{Sig} * * *$ & Sig*** \\
\hline Avoidable unprocessed FW & Not(Sig) & Not(Sig) & Not(Sig) & Sig*** & Sig*** \\
\hline Avoidable unprocessed animal-derived food waste & Not(Sig) & Not(Sig) & Sig**** & Sig*** & Sig*** \\
\hline Avoidable unprocessed vegetable food waste & Not(Sig) & Not(Sig) & Sig*** & Sig*** & Sig*** \\
\hline Unavoidable food waste & Not(Sig) & Not(Sig) & Not(Sig) & Sig* & Sig* \\
\hline Unavoidable animal-derived food waste & Not(Sig) & Not(Sig) & Sig*** & Sig*** & $\operatorname{Sig} * * *$ \\
\hline Unavoidable vegetable food waste & Not(Sig) & Not(Sig) & Sig* & Sig* & Sig* \\
\hline
\end{tabular}

*** Very high significance probability $(p<0.001)$.

$59 * *$ High significance probability $(0.001<p<0.1)$.

$60 \quad *$ significance probability $(0.05<p<0.001)$.

$61 N \operatorname{Not}($ Sig) no significance probability $(p>0.05)$.. 
Table SM 9: Estimated coefficients, 95\% confidence interval and statistically significant of the logistic regression that predict the probability of generating food waste in Danish single-family home

\begin{tabular}{|c|c|c|c|c|c|c|}
\hline \multirow[t]{2}{*}{ Food waste fractions } & \multirow[t]{2}{*}{ Household size } & \multirow[t]{2}{*}{$\mathrm{OR}^{\mathrm{a}}$} & \multirow[t]{2}{*}{ Std. error $^{b}$} & \multicolumn{2}{|c|}{ Confidence interval (95\%) } & \multirow[t]{2}{*}{ P-value } \\
\hline & & & & Lower & Upper & \\
\hline \multirow[t]{3}{*}{ Avoidable food waste } & Intercept (1 person) & 8.5 & 1.4 & 4.64 & 17.45 & $<0.001$ \\
\hline & 2 persons & 3.46 & 1.59 & 1.38 & 8.7 & 0.00747 \\
\hline & $<2$ persons & 22.41 & 2.19 & 5.78 & 147.55 & $<0.001$ \\
\hline \multirow[t]{3}{*}{$\begin{array}{l}\text { Avoidable processed food } \\
\text { wase }\end{array}$} & Intercept (1 person) & 0.94 & 1.23 & 0.63 & 1.4 & 0.758 \\
\hline & 2 persons & 3.92 & 1.28 & 2.41 & 6.4 & $<0.001$ \\
\hline & $<2$ persons & 19.33 & 1.36 & 10.73 & 36.06 & $<0.001$ \\
\hline \multirow{3}{*}{$\begin{array}{l}\text { Avoidable animal-derived } \\
\text { food waste }\end{array}$} & Intercept (1 person) & 0.48 & 1.24 & 0.31 & 0.74 & $<0.001$ \\
\hline & 2 persons & 3 & 1.28 & 1.86 & 4.92 & $<0.001$ \\
\hline & $<2$ persons & 10.9 & 1.3 & 6.61 & 18.33 & $<0.001$ \\
\hline \multirow{3}{*}{$\begin{array}{l}\text { Avoidable vegetable processed } \\
\text { food waste }\end{array}$} & Intercept (1 person) & 0.67 & 1.23 & 0.44 & 1 & 0.0529 \\
\hline & 2 persons & 2.65 & 1.27 & 1.66 & 4.27 & $<0.001$ \\
\hline & $<2$ persons & 7.2 & 1.28 & 4.44 & 11.83 & $<0.001$ \\
\hline \multirow[t]{3}{*}{ NProcpk } & Intercept (1 person) & 5.79 & 1.34 & 3.39 & 10.65 & $<0.001$ \\
\hline & 2 persons & 3.58 & 1.49 & 1.63 & 7.88 & 0.00136 \\
\hline & $<2$ persons & 16.38 & 1.79 & 5.71 & 58.94 & $<0.001$ \\
\hline \multirow[t]{3}{*}{ AnNPkr } & Intercept (1 person) & 1.02 & 1.23 & 0.68 & 1.53 & 0.918 \\
\hline & 2 persons & 2.52 & 1.27 & 1.57 & 4.06 & $<0.001$ \\
\hline & $<2$ persons & 4.97 & 1.28 & 3.07 & 8.1 & $<0.001$ \\
\hline \multirow[t]{3}{*}{ VeNPkr } & Intercept (1 person) & 3.32 & 1.28 & 2.1 & 5.47 & $<0.001$ \\
\hline & 2 persons & 2.86 & 1.37 & 1.54 & 5.26 & $<0.001$ \\
\hline & $<2$ persons & 28.55 & 1.75 & 10.56 & 99.8 & $<0.001$ \\
\hline \multirow[t]{3}{*}{ UAvoidkr } & Intercept (1 person) & 18 & 1.58 & 8.11 & 51.09 & $<0.001$ \\
\hline & 2 persons & 2.36 & 1.82 & 0.68 & 7.56 & 0.15146 \\
\hline & $<2$ persons & 10.58 & 2.33 & 2.24 & 74.73 & 0.00523 \\
\hline \multirow[t]{3}{*}{ AnUkr } & Intercept (1 person) & 2.52 & 1.26 & 1.63 & 4 & $<0.001$ \\
\hline & 2 persons & 2.48 & 1.33 & 1.42 & 4.29 & 0.00128 \\
\hline & $<2$ persons & 2.98 & 1.32 & 1.72 & 5.12 & $<0.001$ \\
\hline \multirow[t]{3}{*}{ VeUkr } & Intercept (1 person) & 10.88 & 1.45 & 5.62 & 24.38 & $<0.001$ \\
\hline & 2 persons & 2.7 & 1.63 & 1 & 7.06 & 0.0423 \\
\hline & $<2$ persons & 6.95 & 1.79 & 2.26 & 23.49 & $<0.001$ \\
\hline \multirow[t]{3}{*}{ AnAvoidkr } & Intercept (1 person) & 1.38 & 1.23 & 0.92 & 2.08 & 0.125 \\
\hline & 2 persons & 3.37 & 1.29 & 2.04 & 5.57 & $<0.001$ \\
\hline & $<2$ persons & 10.41 & 1.34 & 5.91 & 18.72 & $<0.001$ \\
\hline \multirow[t]{3}{*}{ VeAvoidkr } & Intercept (1 person) & 4.94 & 1.32 & 2.97 & 8.76 & $<0.001$ \\
\hline & 2 persons & 2.47 & 1.42 & 1.23 & 4.88 & 0.00955 \\
\hline & $<2$ persons & 25.65 & 1.9 & 8.31 & 112.18 & $<0.001$ \\
\hline \multirow[t]{3}{*}{ Ankr } & Intercept (1 person) & 6.92 & 1.36 & 3.93 & 13.34 & $<0.001$ \\
\hline & 2 persons & 7.18 & 1.67 & 2.7 & 21.16 & $<0.001$ \\
\hline & $<2$ persons & 6.01 & 1.58 & 2.46 & 15.17 & $<0.001$ \\
\hline \multirow[t]{3}{*}{ Vekr } & Intercept (1 person) & 46.5 & 2.04 & 14.73 & 282.22 & $<0.001$ \\
\hline & 2 persons & 1.61 & 2.4 & 0.22 & 8.4 & 0.5845 \\
\hline & $<2$ persons & 8.22 & 3.42 & 0.78 & 177.89 & 0.0869 \\
\hline
\end{tabular}

${ }^{a}:$ The estimate of the odds ratios.

$<2$ persons

8.22

3.42

0.78

177.89

${ }^{b}:$ The estimate of the standard error

${ }^{c}$ : Transformed (exponential) $95 \%$ confidence interval 
Table SM 10: Uncertainty analysis for food waste generation (wet mass basis): Bootstrapping regression results for dataset including only household that generated food waste (mass of food waste is higher than zero)

\begin{tabular}{|c|c|c|c|c|c|c|c|c|c|}
\hline \multirow{4}{*}{ Food waste } & \multirow{4}{*}{ Household size } & \multicolumn{8}{|c|}{ Statistical parameters } \\
\hline & & \multicolumn{4}{|c|}{ Wet mass per household per week } & \multicolumn{4}{|c|}{ Wet mass per person per week } \\
\hline & & \multirow[b]{2}{*}{ original } & \multirow[b]{2}{*}{ bootSE ${ }^{b}$} & \multicolumn{2}{|c|}{$95 \% \mathrm{CI}^{\mathrm{a}}$} & \multirow[b]{2}{*}{ original } & \multirow[b]{2}{*}{ bootSE ${ }^{b}$} & \multicolumn{2}{|c|}{$95 \% \mathrm{CI}^{\mathrm{a}}$} \\
\hline & & & & Lower & Upper & & & Lower & Upper \\
\hline \multirow{4}{*}{ Processed FW } & (Intercept) & 0.356 & 0.045 & 0.265 & 0.446 & 0.319 & 0.041 & 0.240 & 0.397 \\
\hline & pers2 & 0.181 & 0.058 & 0.064 & 0.296 & -0.066 & 0.043 & -0.148 & 0.016 \\
\hline & pers3 & 0.348 & 0.085 & 0.183 & 0.511 & -0.076 & 0.046 & -0.164 & 0.012 \\
\hline & pers4+ & 0.861 & 0.077 & 0.709 & 1.015 & -0.025 & 0.042 & -0.107 & 0.056 \\
\hline \multirow{4}{*}{$\begin{array}{l}\text { Avoidable } \\
\text { animal-derived } \\
\text { processed FW }\end{array}$} & (Intercept) & 0.295 & 0.049 & 0.201 & 0.394 & 0.235 & 0.049 & 0.135 & 0.329 \\
\hline & pers 2 & -0.014 & 0.051 & -0.116 & 0.088 & -0.106 & 0.049 & -0.200 & -0.005 \\
\hline & pers 3 & 0.109 & 0.065 & -0.021 & 0.234 & -0.099 & 0.051 & -0.197 & 0.005 \\
\hline & pers4+ & 0.298 & 0.057 & 0.182 & 0.411 & -0.090 & 0.049 & -0.184 & 0.011 \\
\hline \multirow{4}{*}{$\begin{array}{l}\text { Avoidable } \\
\text { vegetable } \\
\text { processed FW }\end{array}$} & (Intercept) & 0.182 & 0.024 & 0.136 & 0.228 & 0.168 & 0.022 & 0.125 & 0.210 \\
\hline & pers2 & 0.195 & 0.036 & 0.123 & 0.263 & 0.008 & 0.024 & -0.038 & 0.055 \\
\hline & pers 3 & 0.260 & 0.053 & 0.152 & 0.362 & -0.018 & 0.027 & -0.068 & 0.033 \\
\hline & pers4+ & 0.468 & 0.046 & 0.373 & 0.557 & -0.006 & 0.023 & -0.050 & 0.040 \\
\hline \multirow{4}{*}{$\begin{array}{l}\text { Avoidable } \\
\text { vegetable } \\
\text { unprocessed FW }\end{array}$} & (Intercept) & 0.320 & 0.037 & 0.246 & 0.393 & 0.274 & 0.037 & 0.196 & 0.345 \\
\hline & pers2 & 0.037 & 0.042 & -0.044 & 0.122 & -0.110 & 0.039 & -0.185 & -0.028 \\
\hline & pers3 & 0.122 & 0.049 & 0.026 & 0.221 & -0.125 & 0.039 & -0.200 & -0.044 \\
\hline & pers4+ & 0.144 & 0.046 & 0.057 & 0.235 & -0.156 & 0.038 & -0.230 & -0.076 \\
\hline
\end{tabular}

${ }^{a}$ :Confidence interval.

${ }^{b}$ The bootstrapped estimates of standard error

Table SM 11: Uncertainty analysis for food waste generation (wet mass basis): Bootstrapping regression results for dataset including both households that generated and not food waste (raw data)

\begin{tabular}{|c|c|c|c|c|c|c|c|c|c|}
\hline \multirow{4}{*}{ Food waste } & \multirow[t]{4}{*}{ Household size } & \multicolumn{8}{|c|}{ Statistical parameters } \\
\hline & & \multicolumn{4}{|c|}{ Wet mass per household per week } & \multicolumn{4}{|c|}{ Wet mass per person per week } \\
\hline & & \multirow[b]{2}{*}{ original } & \multirow[b]{2}{*}{ bootSE ${ }^{b}$} & \multicolumn{2}{|c|}{$95 \% \mathrm{CI}^{\mathrm{a}}$} & \multirow[b]{2}{*}{ original } & \multirow[b]{2}{*}{ bootSE ${ }^{b}$} & \multicolumn{2}{|c|}{$95 \% \mathrm{CI}^{\mathrm{a}}$} \\
\hline & & & & Lower & Upper & & & Lower & Upper \\
\hline \multirow{4}{*}{ Processed FW } & (Intercept) & 0.168 & 0.028 & 0.114 & 0.221 & 0.125 & 0.024 & 0.076 & 0.172 \\
\hline & pers2 & 0.233 & 0.040 & 0.155 & 0.314 & 0.060 & 0.025 & 0.011 & 0.110 \\
\hline & pers3 & 0.455 & 0.069 & 0.325 & 0.586 & 0.089 & 0.029 & 0.031 & 0.146 \\
\hline & pers $4+$ & 0.988 & 0.071 & 0.853 & 1.123 & 0.151 & 0.026 & 0.101 & 0.204 \\
\hline \multirow{4}{*}{$\begin{array}{l}\text { Avoidable } \\
\text { animal-derived } \\
\text { processed FW }\end{array}$} & (Intercept) & 0.067 & 0.015 & 0.036 & 0.096 & 0.045 & 0.010 & 0.026 & 0.063 \\
\hline & pers2 & 0.063 & 0.018 & 0.028 & 0.099 & 0.020 & 0.010 & 0.001 & 0.040 \\
\hline & pers3 & 0.166 & 0.032 & 0.100 & 0.227 & 0.046 & 0.013 & 0.019 & 0.074 \\
\hline & pers4+ & 0.408 & 0.037 & 0.338 & 0.481 & 0.073 & 0.011 & 0.051 & 0.096 \\
\hline \multirow{4}{*}{$\begin{array}{l}\text { Avoidable } \\
\text { vegetable } \\
\text { processed FW }\end{array}$} & (Intercept) & 0.071 & 0.012 & 0.046 & 0.097 & 0.059 & 0.011 & 0.038 & 0.080 \\
\hline & pers2 & 0.140 & 0.024 & 0.091 & 0.188 & 0.044 & 0.013 & 0.018 & 0.070 \\
\hline & pers3 & 0.220 & 0.036 & 0.150 & 0.291 & 0.048 & 0.016 & 0.016 & 0.080 \\
\hline & pers4+ & 0.438 & 0.040 & 0.356 & 0.517 & 0.077 & 0.013 & 0.052 & 0.103 \\
\hline \multirow{4}{*}{$\begin{array}{l}\text { Avoidable } \\
\text { vegetable } \\
\text { unprocessed FW }\end{array}$} & (Intercept) & 0.149 & 0.024 & 0.103 & 0.195 & 0.111 & 0.020 & 0.073 & 0.151 \\
\hline & pers2 & 0.090 & 0.028 & 0.033 & 0.144 & 0.005 & 0.019 & -0.034 & 0.043 \\
\hline & pers3 & 0.187 & 0.039 & 0.109 & 0.262 & 0.009 & 0.021 & -0.034 & 0.049 \\
\hline & pers $4+$ & 0.219 & 0.034 & 0.149 & 0.285 & -0.009 & 0.019 & -0.048 & 0.027 \\
\hline
\end{tabular}

Table SM 12: Comparison between datasets containing or not households that generated food. Difference is between dataset (raw dataset, including household with zero food waste) and dataset including only households that generated food waste.

\begin{tabular}{|c|c|c|c|c|c|}
\hline Food waste fractions & Difference & Bias & $5 \%$ & $95 \%$ & Significance \\
\hline Food waste & -0.022 & 0.005 & -0.289 & 0.232 & \\
\hline Avoidable food waste & -0.071 & 0.002 & -0.262 & 0.105 & \\
\hline Avoidable processed food waste & -0.161 & -0.001 & -0.241 & -0.072 & $*$ \\
\hline Avoidable processed animal-derived food waste & -0.168 & 0.000 & -0.215 & -0.121 & $*$ \\
\hline Avoidable processed vegetable food waste & -0.176 & 0.000 & -0.232 & -0.121 & $*$ \\
\hline Avoidable unprocessed food waste & -0.072 & 0.002 & -0.202 & 0.074 & \\
\hline Avoidable unprocessed animal-derived food waste & -0.130 & 0.000 & -0.188 & -0.074 & $*$ \\
\hline Avoidable unprocessed vegetable food waste & -0.101 & 0.000 & -0.220 & 0.032 & \\
\hline Unavoidable food waste & -0.035 & -0.001 & -0.158 & 0.089 & \\
\hline Unavoidable animal-derived food waste & -0.036 & -0.001 & -0.065 & -0.006 & $*$ \\
\hline Unavoidable vegetable food waste & -0.016 & -0.001 & -0.138 & 0.098 & \\
\hline
\end{tabular}


Figure SM 1: Percentage of households that did not generate food waste ("no") in the single-family house area $(\% \mathrm{n} / \mathrm{n})$ A: Avoidable and unavoidable; B Avoidable animal-derived and avoidable vegetable; C: Animal derived and vegetable food waste; D: Avoidable processed and avoidable unprocessed.

A
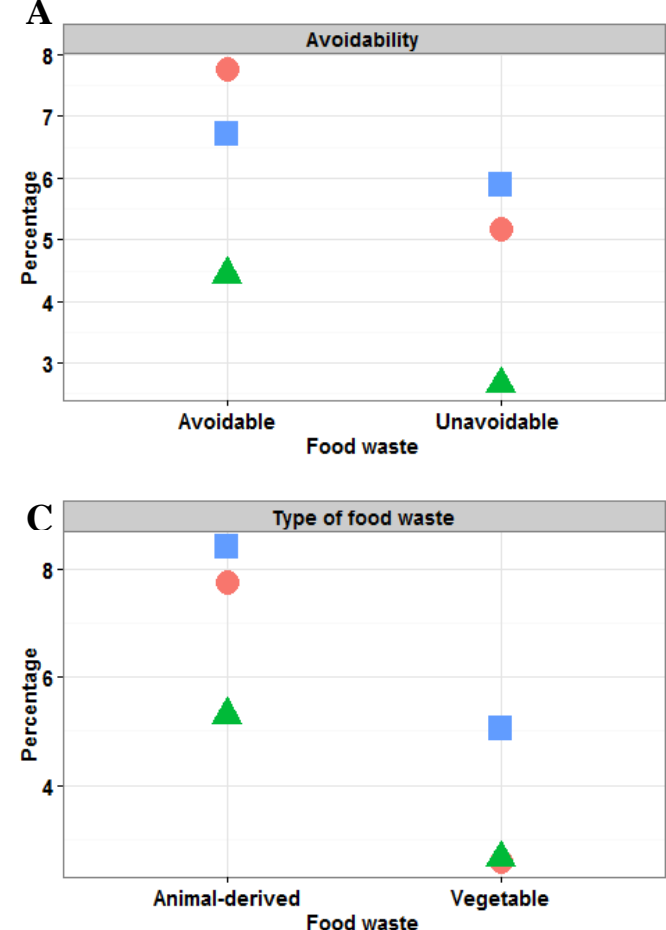

Period

Period 1

Period 2
Period3

Period

Period 1

Period 2

Period3
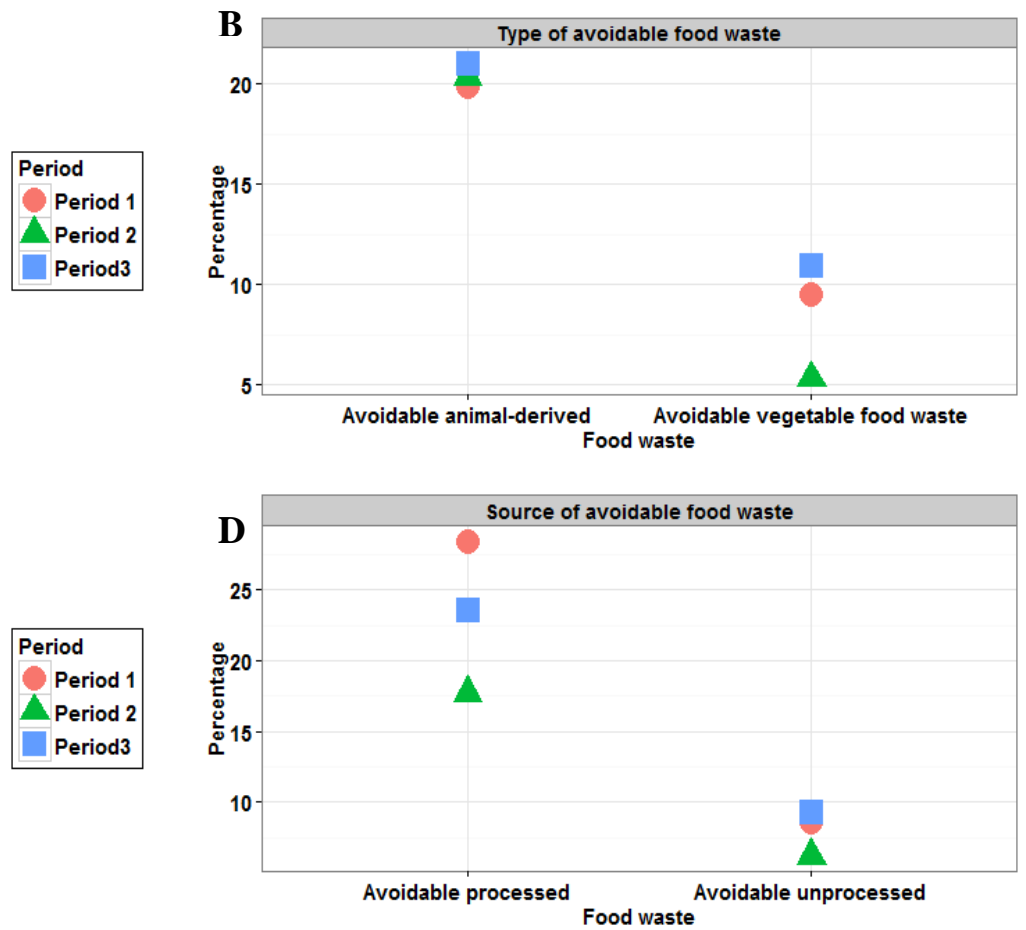
93 Figure SM 2: Summary of the distribution of total food waste (wet mass basis) among single-family houses as

94 function of household size based on $\mathrm{kg}$ per household per week and $\mathrm{kg}$ per person per week
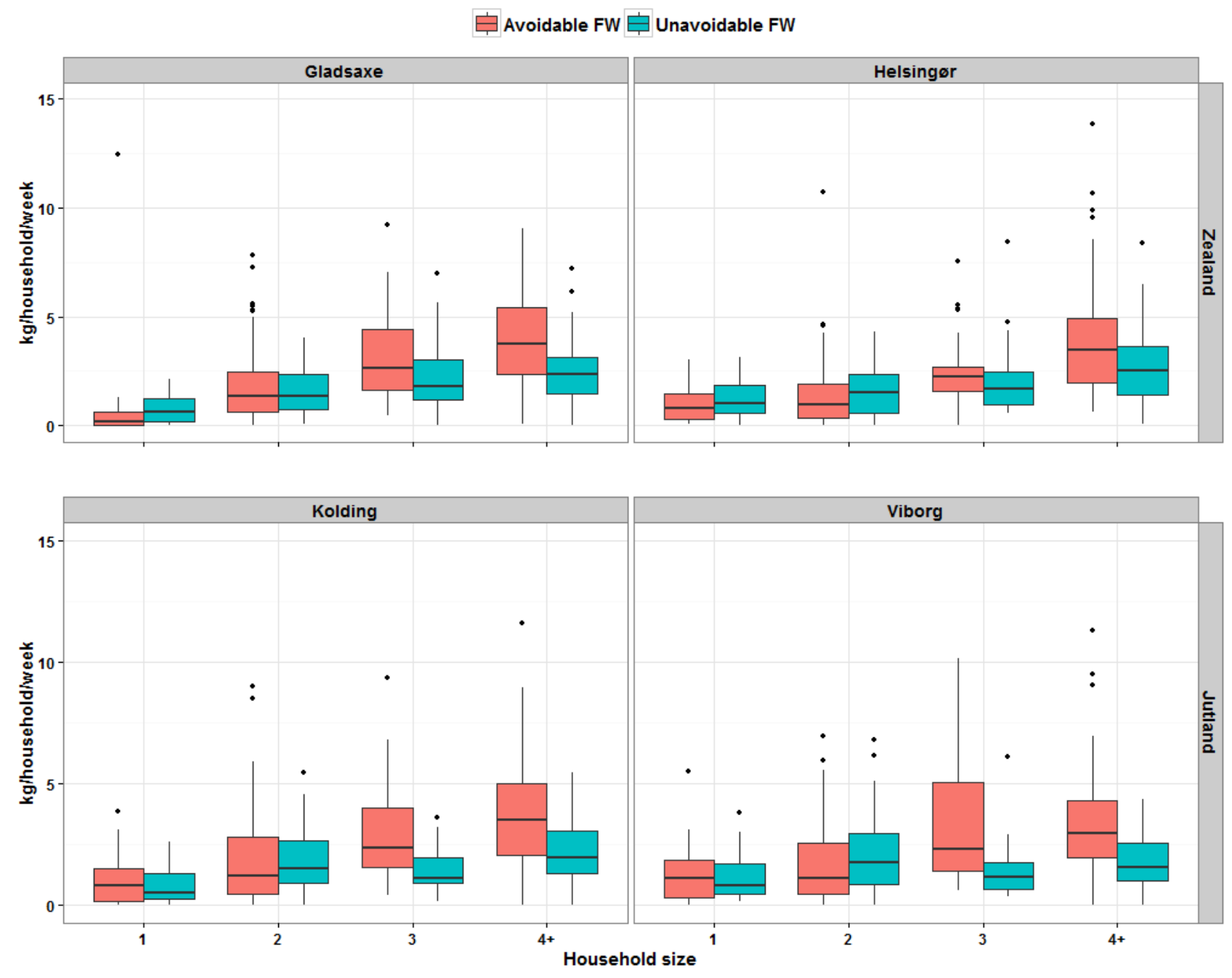

95 
110 Figure SM 3: Percentage of households that did not generate food waste ("no") in the single-family house area $111(\% \mathrm{n} / \mathrm{n})$ : total food waste and other residual household waste

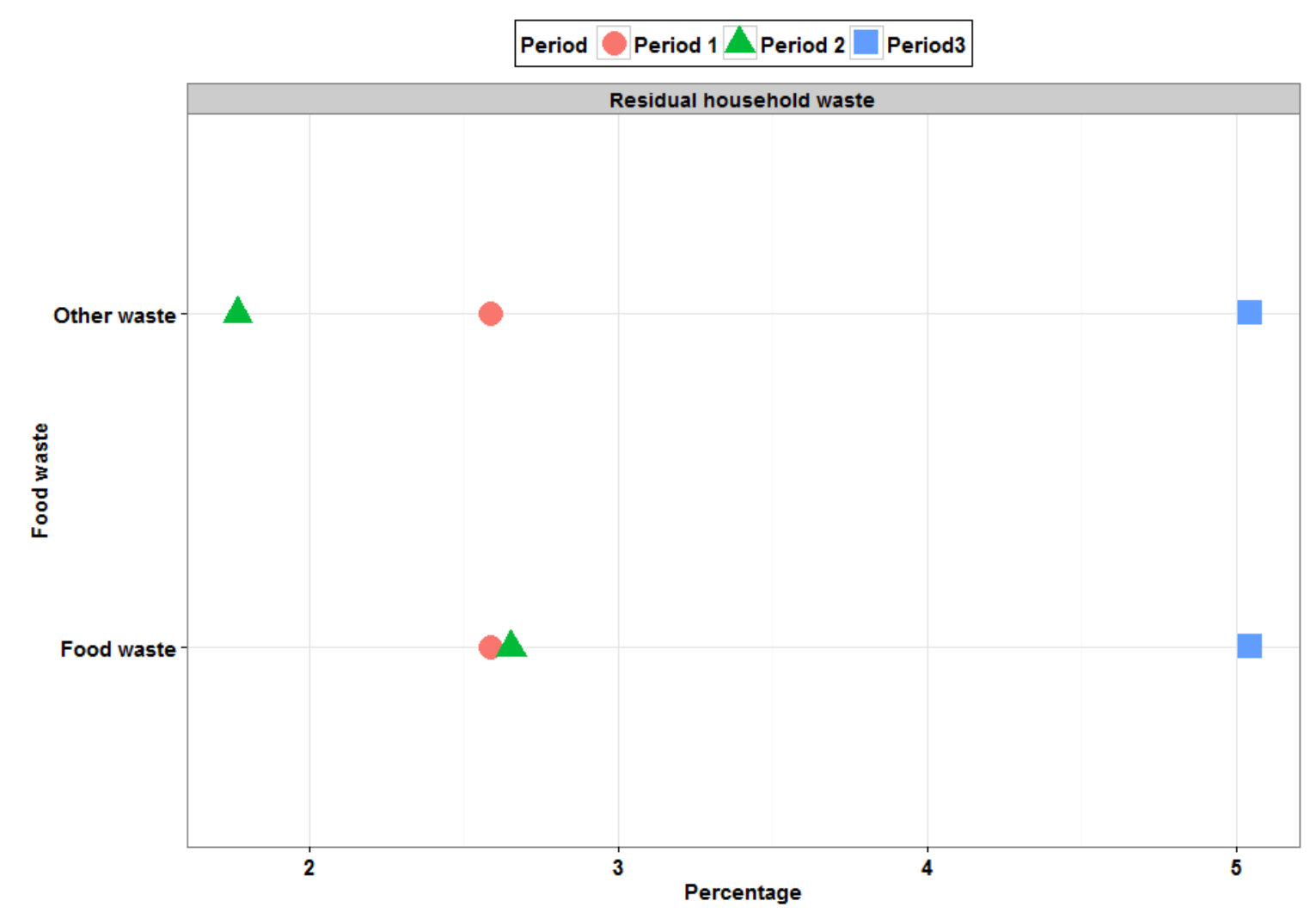


115 Figure SM 4: Percentage of households that did not generate food waste ("no") in the single-family house area $(\% \mathrm{n} / \mathrm{n})$ for the six food waste fractions

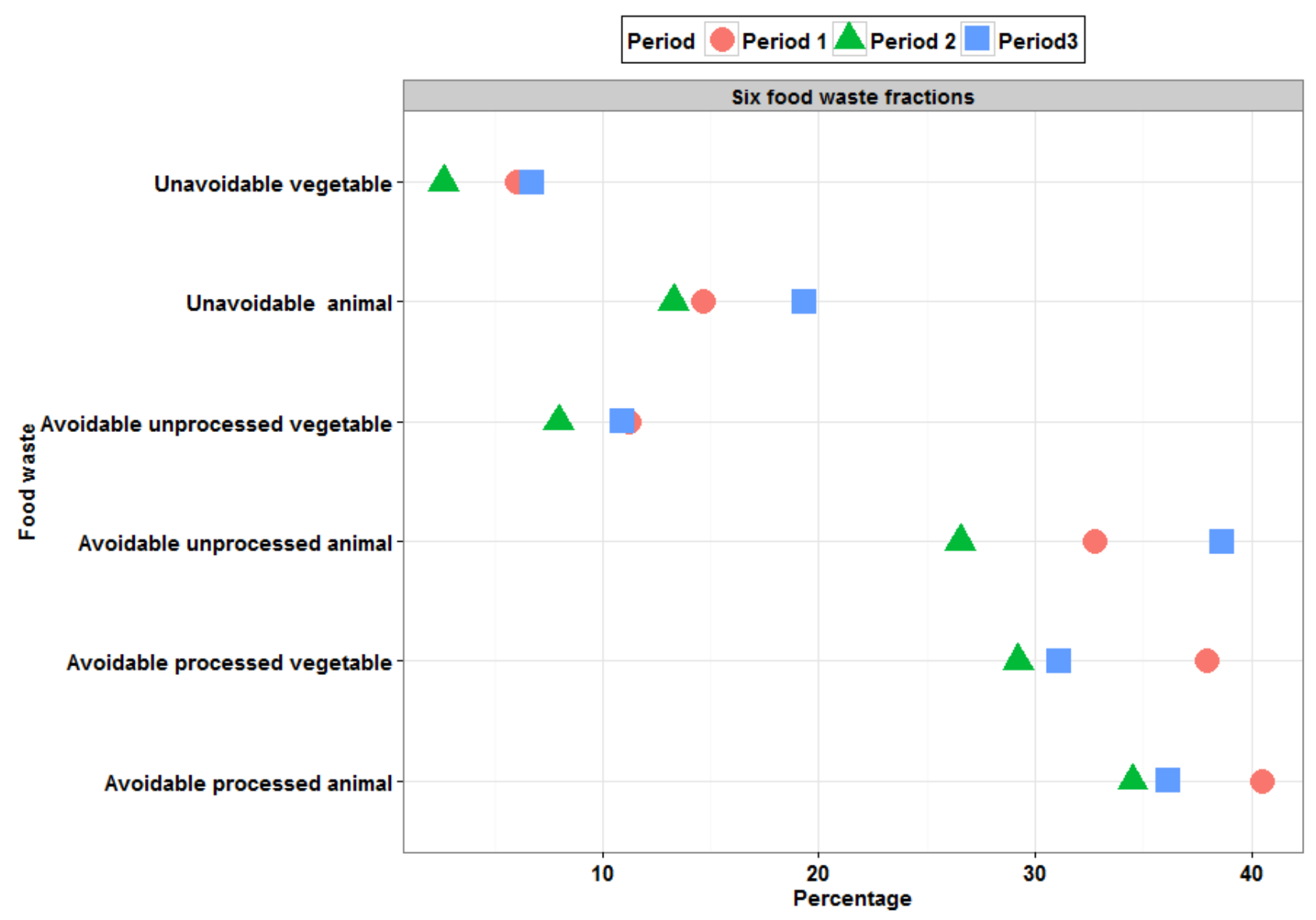


Figure SM 5: Summary of the distribution of total food waste (wet mass basis) among households as function of household size based on $\mathrm{kg}$ per household per week and $\mathrm{kg}$ per person per week
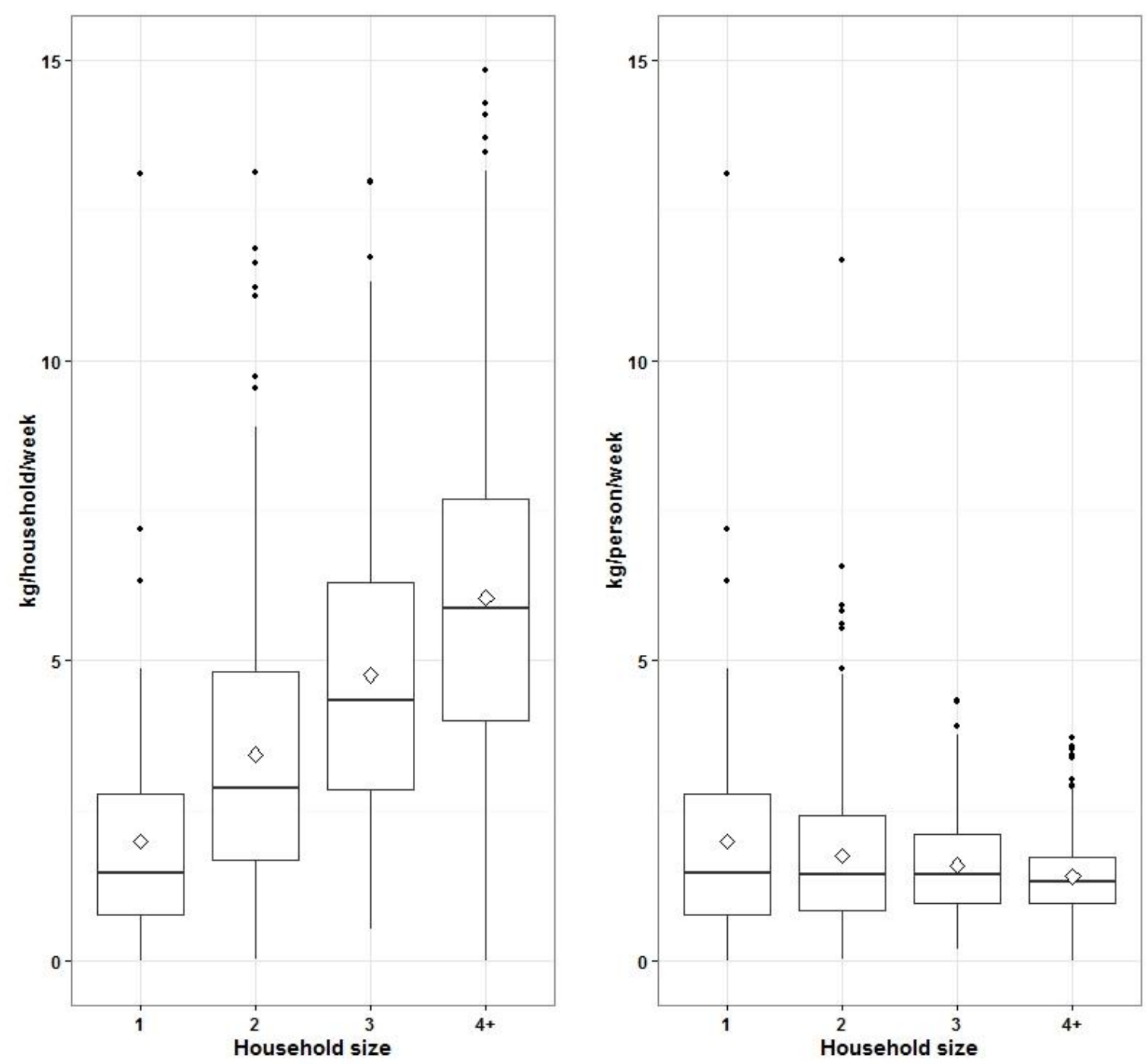